\title{
ACONDICIONAMIENTO DEL MUSEO NACIONAL DE CIENCIAS NATURALES, SALAS DE PALEONTOLOGIA MADRID-ESPAÑA
}

\author{
(ARRANGEMENT OF DE NATIONAL MUSEUM OF NATURAL SCIENCES, \\ PALEONTHOLOGY ROOMS. MADRID, SPAIN)
}

Juan Eizaguirre Diez de Rivera y José M. ${ }^{a}$ Mata Calleja, Arquitectos

Román Alonso Garcia y Yolanda Hernández Miguel, Arquitectos Técnicos

E. T.: Goya, $19 \cdot 28001$ Madrid/Espan̂a

$142-152$

Fecha de recepción: 25.1X-89

\section{RESUMEN}

Tras una breve introducción que marca las peculiaridades del encargo, se procede a analizar, a la vista de los

acontecimientos históricos del pais, la evolución de los modelos edificatorios de la época basados en la utilización del hierro, y la creación de los primeros Museos de Ciencias Naturales, hasta converger ambos con el nacimiento de este edificio.

Una descripción del conjunto conduce a ubicar esta reforma en el ala longitudinal oeste, describiéndose las caracteristicas constructivas existentes antes de la actuación, y dando pie para, en base al análisis, describir la filosofía del acondicionamiento, justificando las actuaciones en base a la recuperación del contenedor primitivo.

Posteriormente se realiza la descripción de la ejecución de la idea mencionada, haciendo hincapié en los estudios estructurales realizados, y acompañando todo el conjunto con una información gráfica.

\section{SUMMARY}

After a brief introduction which explains the characteristics of the professional commission, it is analysed, under the point of view of the historic events in the country, the evolution of the building patterns of the time based in the use of iron and in the appearance of the first Science and Nature Museums, till both converge in the birth of this building.

A description as a whole lead to lie this reform on the west side, showing the original constructive characteristics before the procedure and to allow through analysis to describe the philosophy of the arrangement, in order to recuperate the primitive space container.

Afterwards, a description of the works manager of that idea is made paying special attention on the structural studies and with an important graphic information.

\section{INTRODUCCIÓN}

Antes de comenzar a explicar el acondicionamiento efectuado es imprescindible, para comprenderlo en su

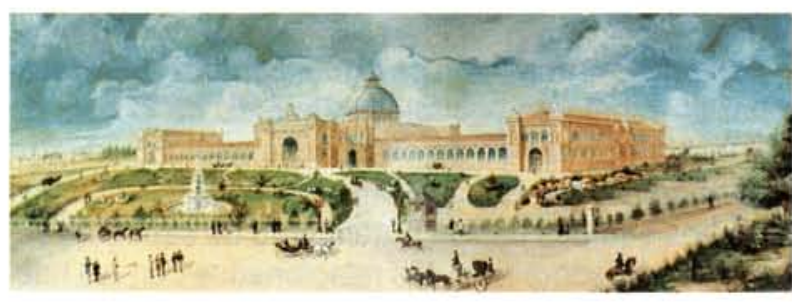

Fig. 1.-La colina de los Chopos, 1900. (c) Consejo Superior de Investigaciones Científicas Licencia Creative Commons 3.0 España (by-nc) conjunto, analizar el encargo que nos hace la Dirección del Museo en octubre de 1985, por medio de la empresa Iberduero, S. A., que estaba dispuesta a dar fondos propios para rehabilitar la nave dedicada a Paleontología del Museo Nacional de Ciencias Naturales.

Una vez coordinados la empresa y la dirección del Museo, dirigido entonces por el Dr. Aguirre, se entrega una idea general de la actuación, con estudio de tiempos para que ésta sea rápida y así evitar el deterioro acelerado del Museo. Se crea el equipo redactor y de colaboradores, y se organiza dentro del Museo el equipo de Paleontólogos a colaborar directamente en la elahttp://informesdelaconstruccion.revistas.csic.es 


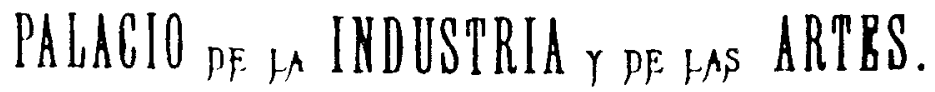

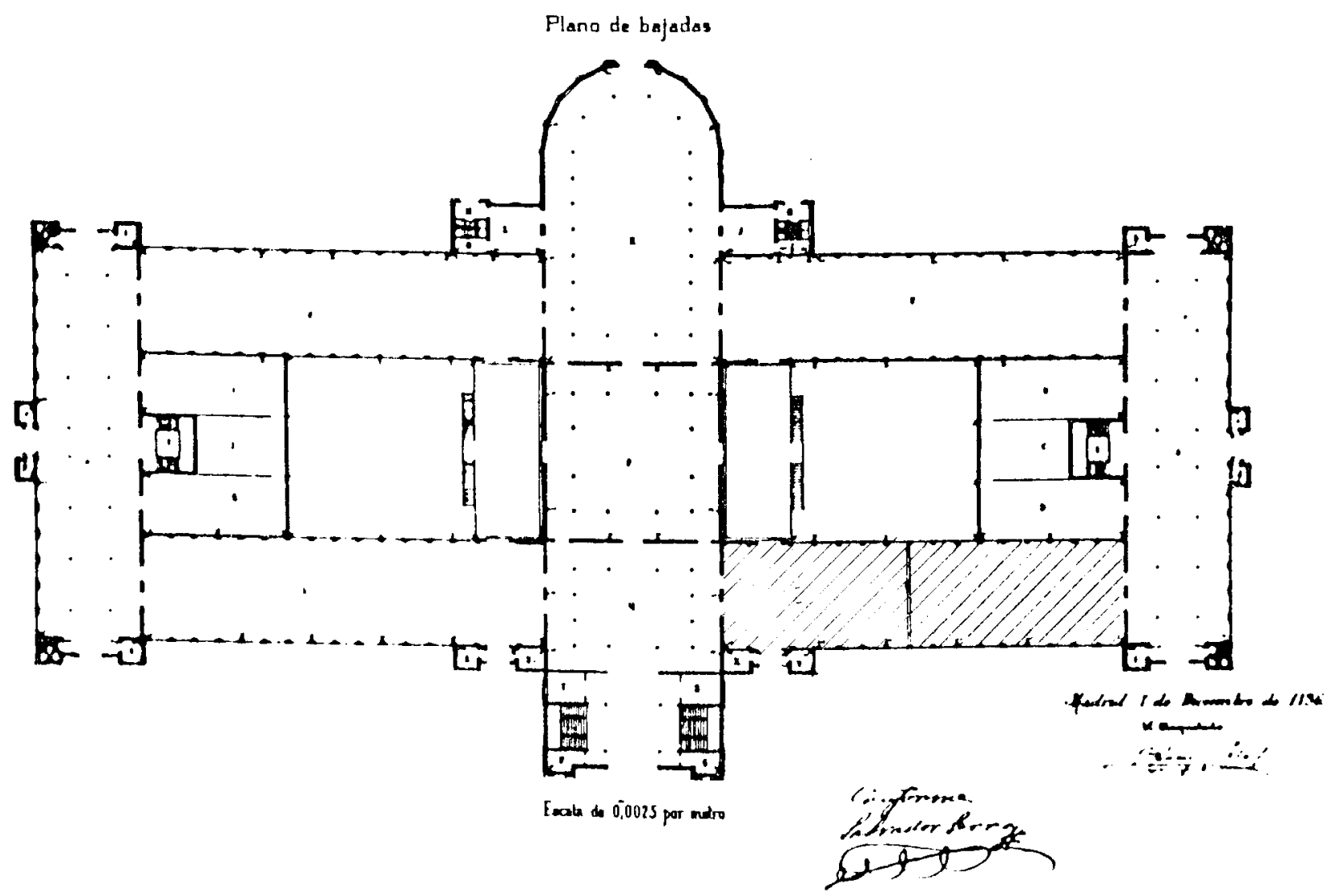

Fig. 2.-Planta primitiva del Museo de Ciencias Naturales.

boración del proyecto. Con la firma del protocolo entre ambas se inicia la fase de redacción del acondicionamiento de la sala de Paleontología, teniendo en cuenta una filosofía de actuación global.

Posteriormente, con el nombramiento de la Dra. Lain como directora, se inician las obras y se encarga la redacción de un segundo proyecto: el acondicionamiento de las Salas de Mineralogia, como espacio intermedio entre el acceso y la sala que se acondicionaba; con ello se lograba una actuación completa en el antiguo Museo de Paleontología, aunque la falta de fondos para realizar esta $2{ }^{2}$ fase obligó a reestructurar y anular parte de las actuaciones que se pretendian acometer, para así lograr una cifra económica que fuera más interesante. No se contemplaba una actuación profunda del vestibulo ni se valoraba la formación de unidades de actuación de apoyo museístico, por lo que hubo que realizar, cuando se facilitaron fondos, un último proyecto que contemplara aquellos extremos no tenidos en cuenta físicamente, aunque sí en el estudio global.

Gracias al planteamiento inicial, el conjunto de las actuaciones han sido solapadas, al definirse, como ya se ha indicado, la filosofía de una posible actuación, aun- que han existido múltiples dificultades - no sólo eco. nómicas - para completar el trabajo.

Este planteamiento inicial sustituye al esquema director que debia haberse desarrollado, y que de hecho se redactó en base al Informe para una reestructuración del Museo Nacional de Ciencias Naturales, en donde se fijaban los objetivos del Museo.

El mayor inconveniente del acondicionamiento estribaba en que fuera puntual, no teniendo en cuenta, por imposibilidad física, cualquier actuación de trabazón con el espacio ocupado por los Ingenieros Industriales. Por ello el tratamiento y la base de actuación desde el principio es crear un contenedor con recuperación máxima de las condiciones primitivas, de tal forma que éste sea útil en el futuro del edificio.

La posterior contratación de otros técnicos para desarrollar el trabajo de acondicionamiento de la sala de zoología, y la creación de otras dependencias (dentro del plan creado por el actual director), aconsejó la unión de ambos equipos para el tratamiento de aspectos determinados y, sobre todo, los relacionados con los huecos. 


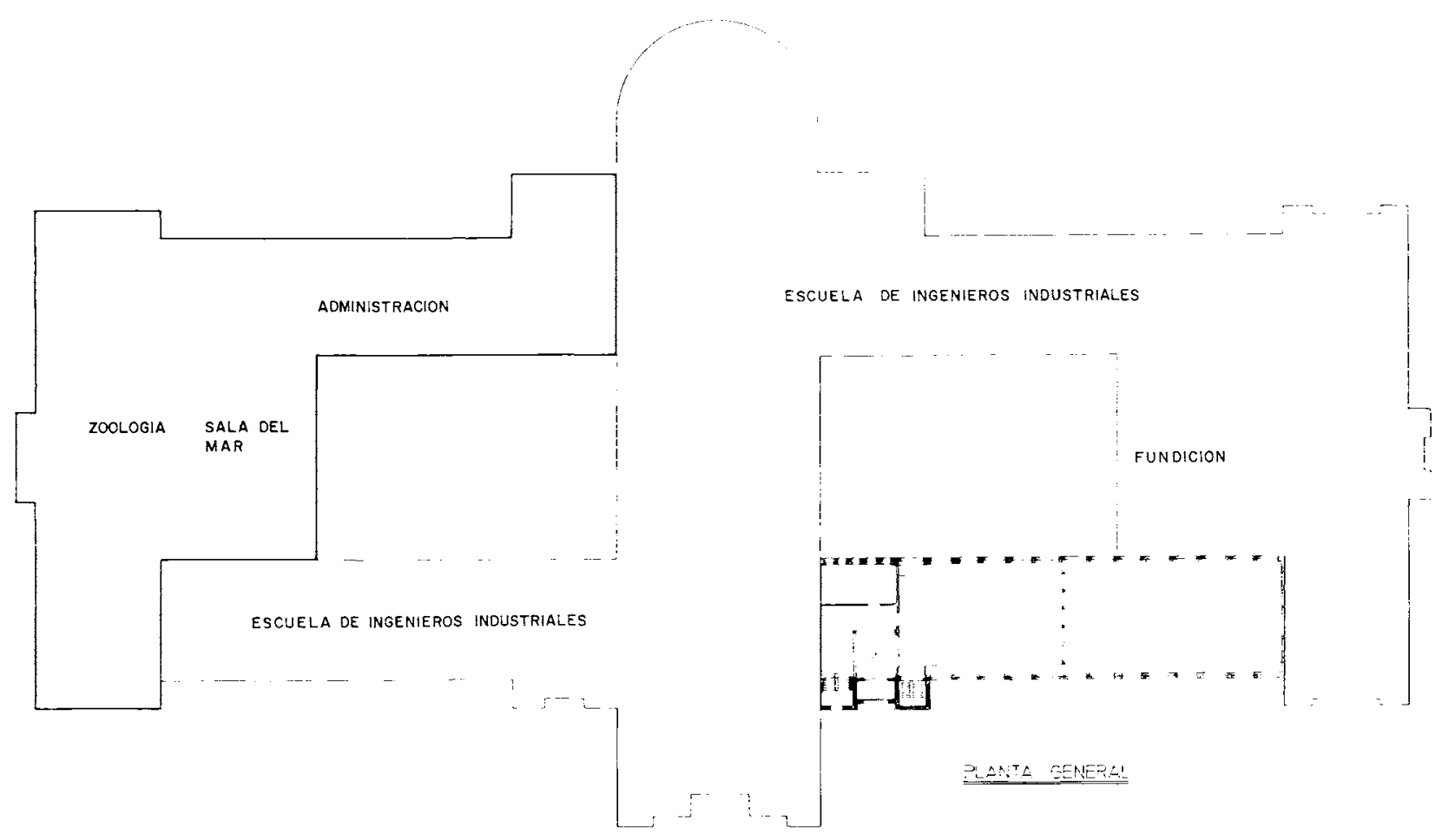

Fig. 3.-Distribución actual.

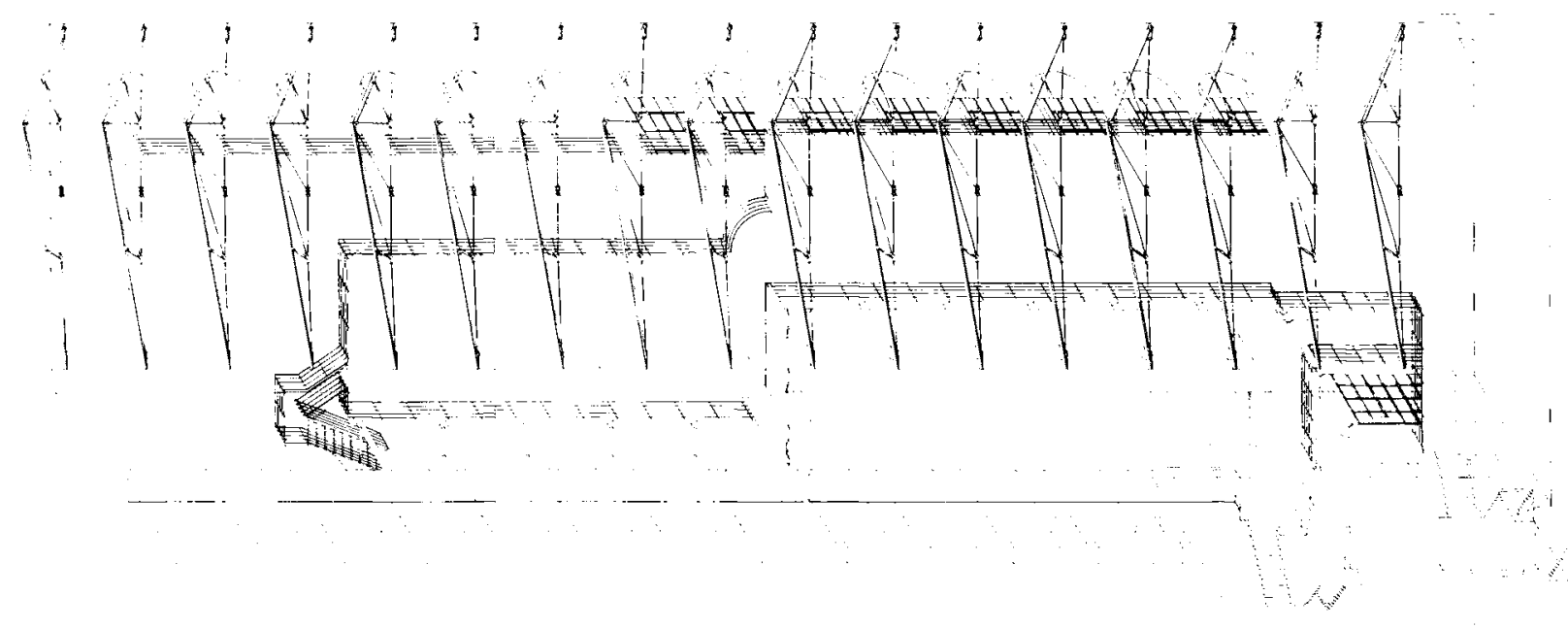

Fig. 4.-Perspectiva axonométrica después del acondicionamiento.

\section{RESEÑA HISTÓRICA}

Como paso previo a nuestra intervención, realizamos un estudio histórico y gráfico, el cual nos permitiese conocer los acontecimientos, los informes, los arqui- tectos que intervinieron después de su terminación en los cambios de uso y propuestas.

Consideramos los acontecimientos históricos que se sucedieron en Europa antes de la construcción del edificio que nos ocupa: 

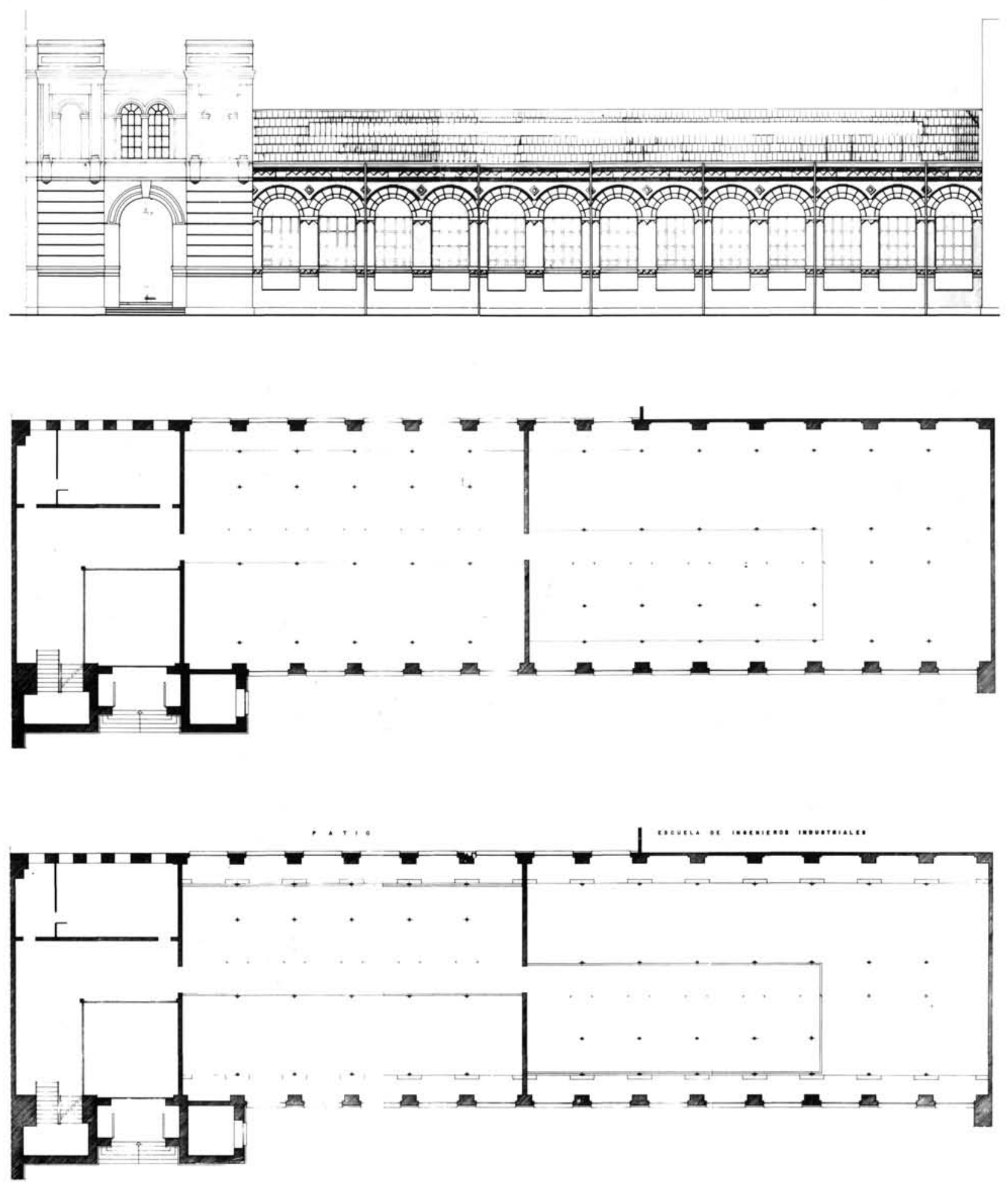

Fig. 5.-Alzado y plantas del estado primitivo.

La primera exposición de productos de la industria nacional se realiza en Francia, en 1798. El eco de este hecho no tarda en dejarse sentir y se suceden en toda Europa, durante todo el siglo XIX, multitud de exposiciones dedicadas a la industria y a las artes, entre ellas la $1{ }^{a}$ exposición universal en 1862 , celebrada en Londres, a la que sucederán otras hasta cerrar el período de estos monumentales certámenes con la exposición internacional de Paris en 1878.
España durante ese periodo histórico no participa en ninguna de las exposiciones mencionadas, dada la intranquilidad política del pais que se encuentra sumido en disturbios.

Al poderoso vigor de Francia en 1798 corresponde en España el débil reinado de Carlos IV con sucesivas guerras, al cual le sucede Fernando VII con la Guerra de Ia Independencia, hasta llegar a Doña Isabel II bajo cu- 

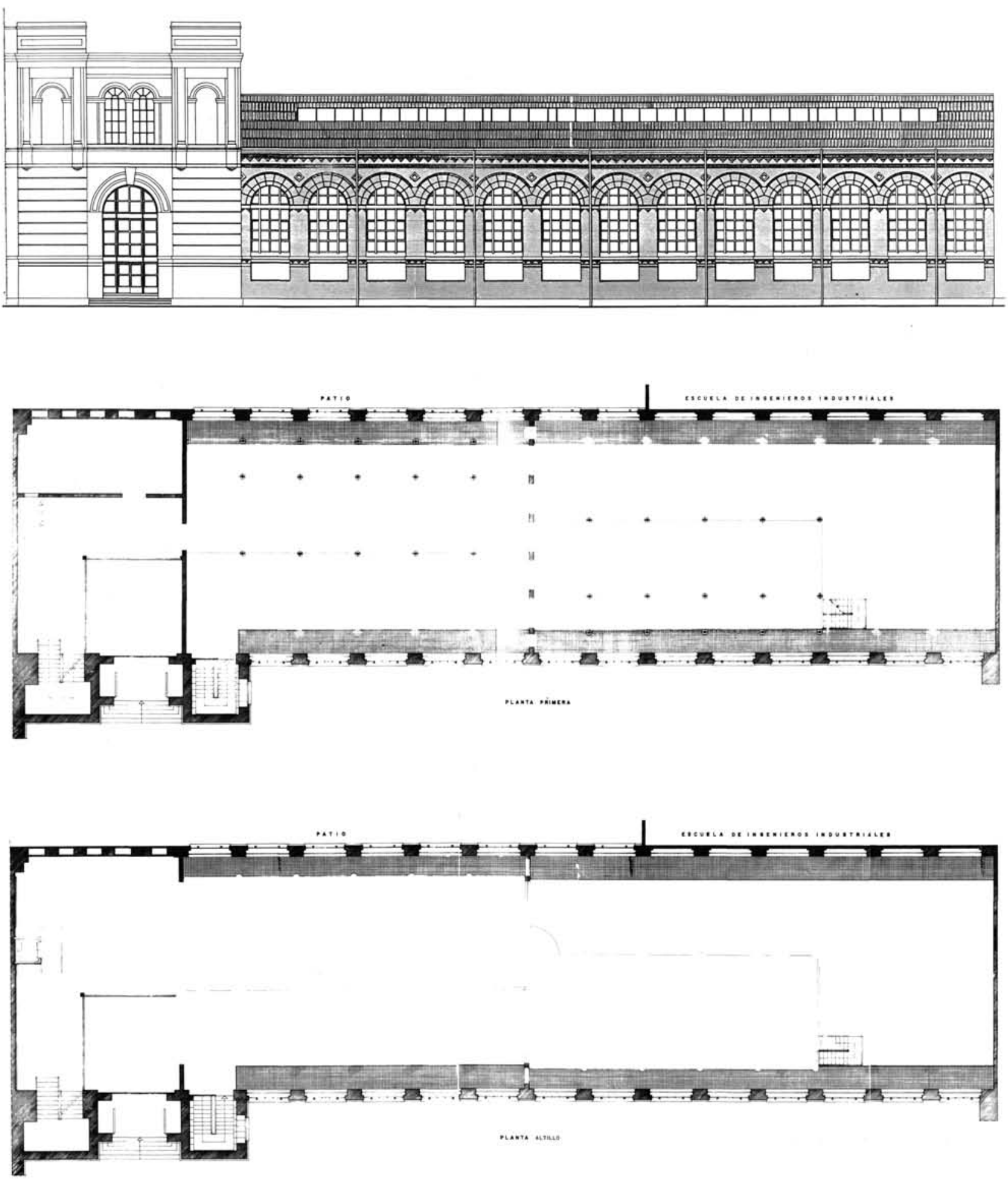

Fig. 6.-Alzado y plantas después del acondicionamiento.

yo reinado se normaliza la situación interna. En 1857 tiene lugar la primera exposición que se realiza en nuestro pais dedicada a las artes y a la industria. Posteriormente se sucedieron otras con distintos objetivos, hasta llegar al reinado de Don Amadeo, durante el cual se celebraron las exposiciones de Bellas Artes de 1875, vinicola de 1877 y otra de Bellas Artes en 1879.

Así se llega al año 1881, en que la Junta Central para

la Exposición General Española de la Industria y de las Artes, acuerda la realización del concurso para la construcción de un edificio dotado de las necesarias condiciones con objeto de albergar la mencionada exposición.

El concurso es ganado por el arquitecto don Fernando de la Torriente, al que se le encarga el proyecto y dirección de las obras, acabándose el edificio en 1887 


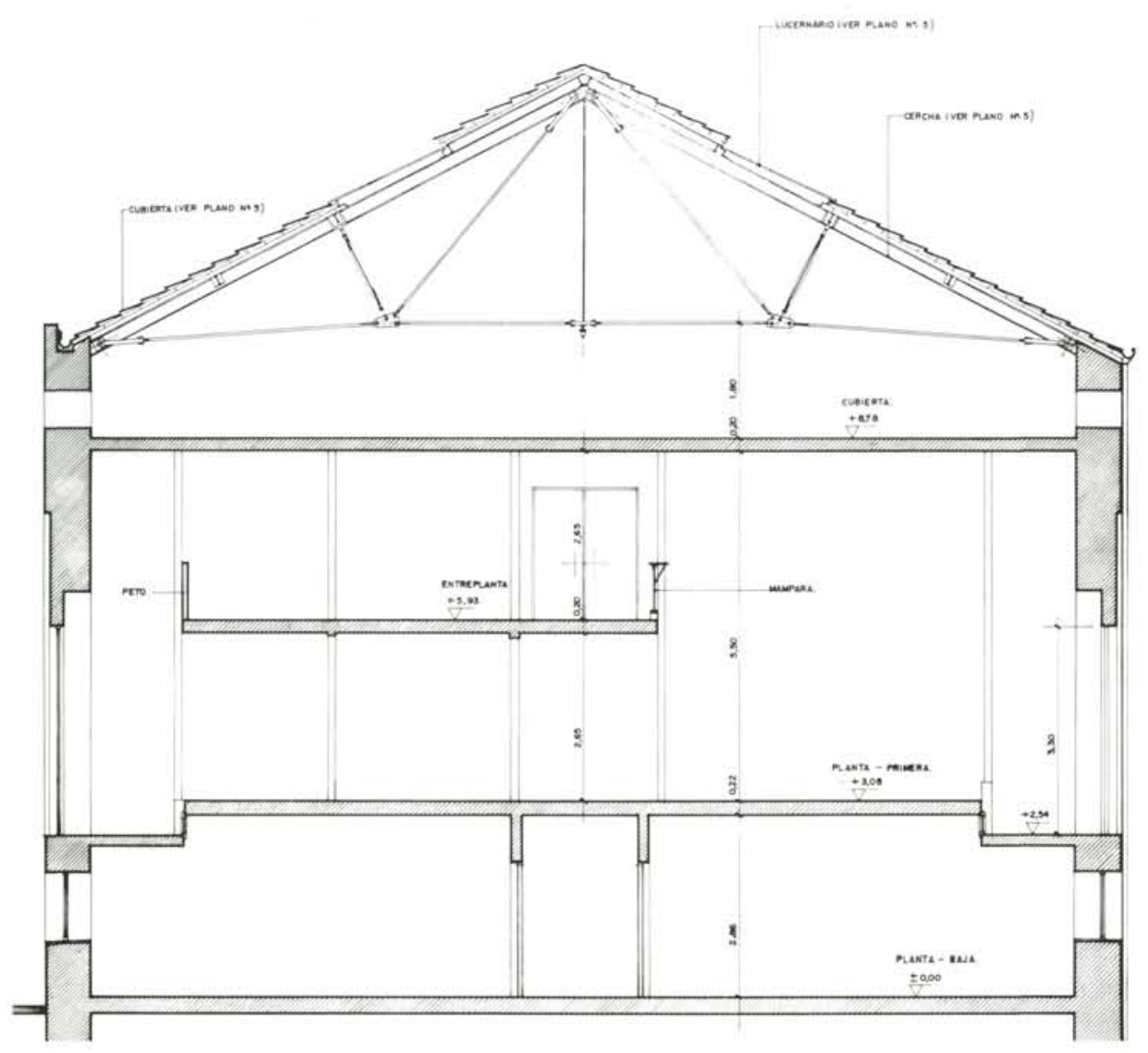

Fig. 7.-Sección transversal del estado primitivo.

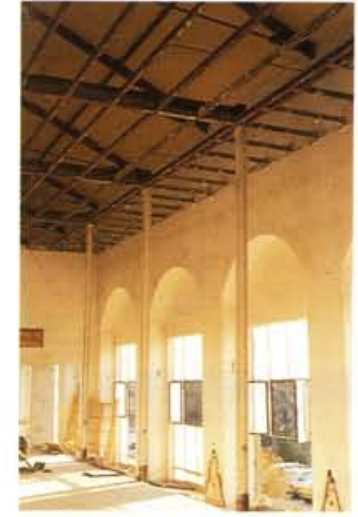

Fig. 8.-Detalle sala paleontologia durante la reforma donde se ve la estructura del desván y el muro transversal que divide la nave en dos salas, construidas entre 1930 y 1935.

por don Emilio Boix colaborador del anterior, debido al fallecimiento de aquél.

Se elige como emplazamiento del nuevo edificio unos terrenos sensiblemente accidentados, que ocupan la derecha del Paseo de la Castellana en Madrid, en una zona denominada Altos del Hipódromo.

La solución que se adoptó fue crear un plano de nivel

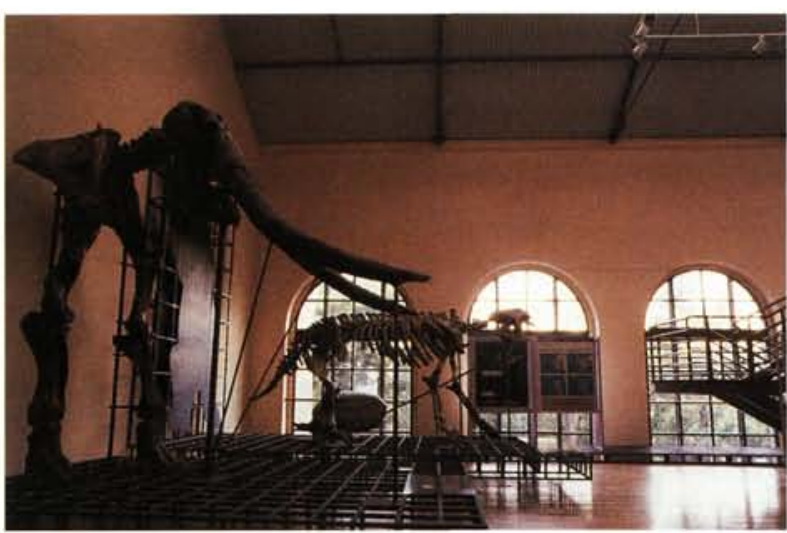

Fig. 9.-Sección después del acondicionamiento.

intermedio sobre el Paseo de la Castellana y que colo. có al edificio respecto a aquél, en una situación elevada, ganando en perspectiva.

Para realizar una descripción del edificio en su origen, tenemos que basarnos en el único documento que existe escrito, la memoria del anteproyecto, que se realizó para participar en el concurso al que hemos hecho referencia anteriormente, ya que los planos encontrados 


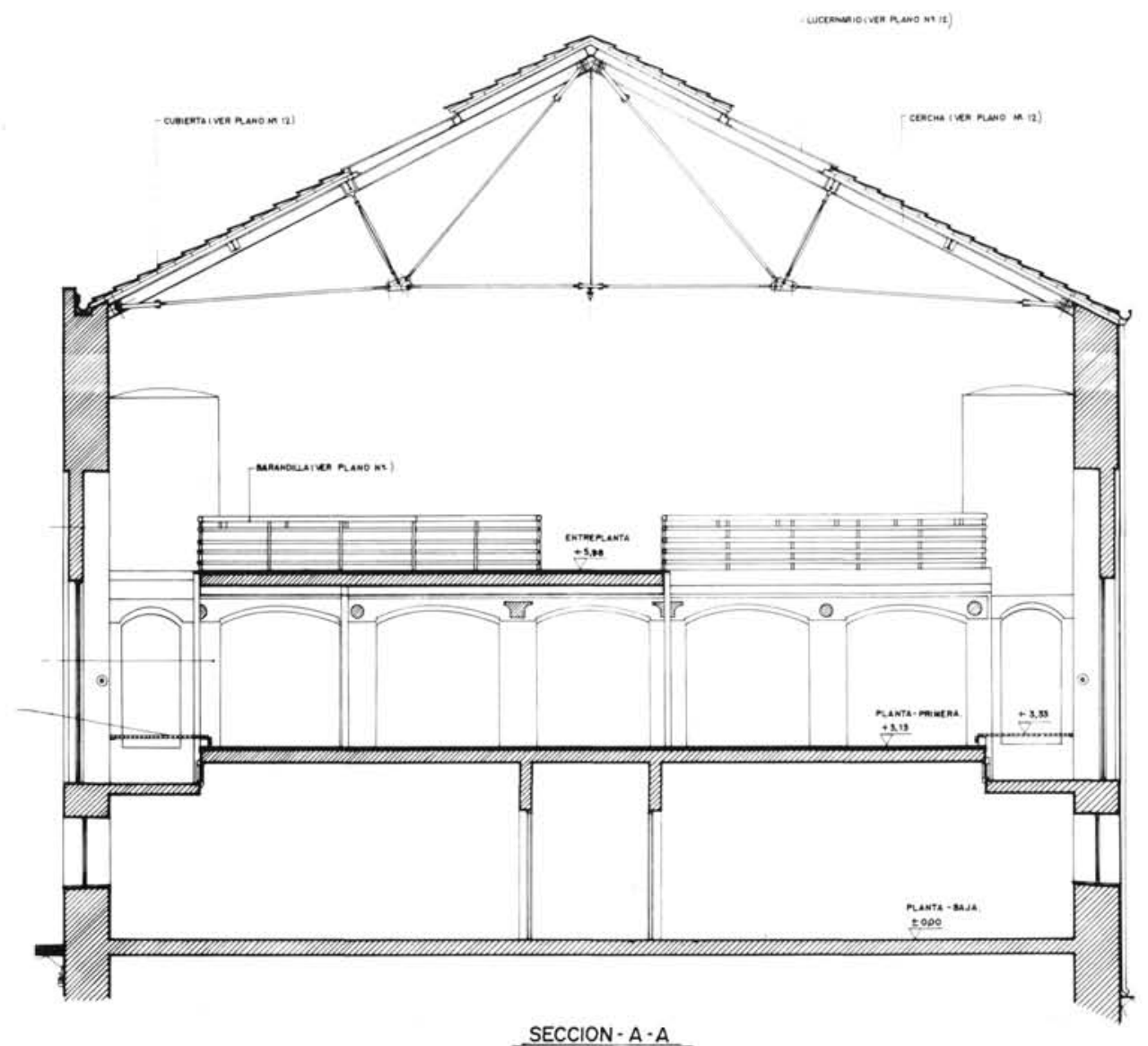

Fig. 10.-Sección transversal. Estado actual.

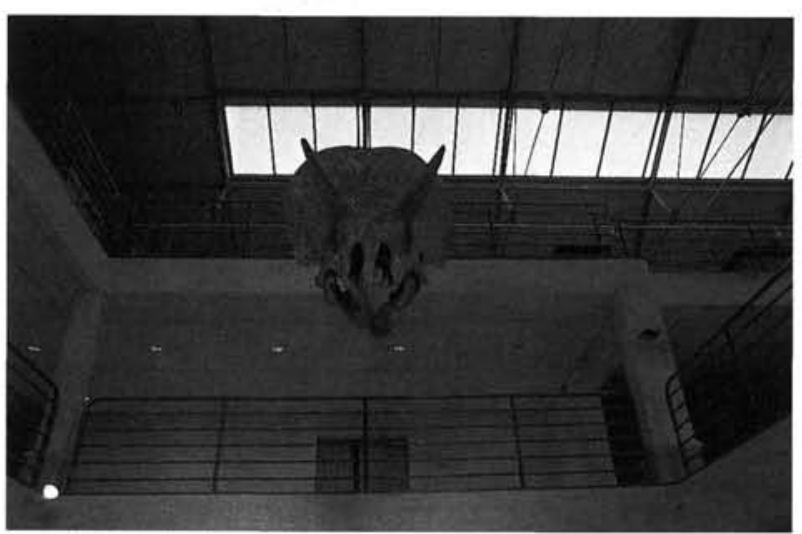

Fig. 11.-El vestibulo, en su estado primitivo, era triste y ocultaba con paramentos, mármoles y carpintería el acceso al muro.

del edificio en el Archivo Histórico, dependiente de la Universidad de Alcalá de Henares, corresponden a una primera reforma realizada en 1896.

El edificio se ordena según dos ejes ortogonales: el primero sirve de eje transversal de simetría y es normal al Paseo de la Castellana, y el segundo es el eje longitudinal del edificio.

(c) Consejo Superior de Investigaciones Científicas Licencia Creative Commons 3.0 España (by-nc)

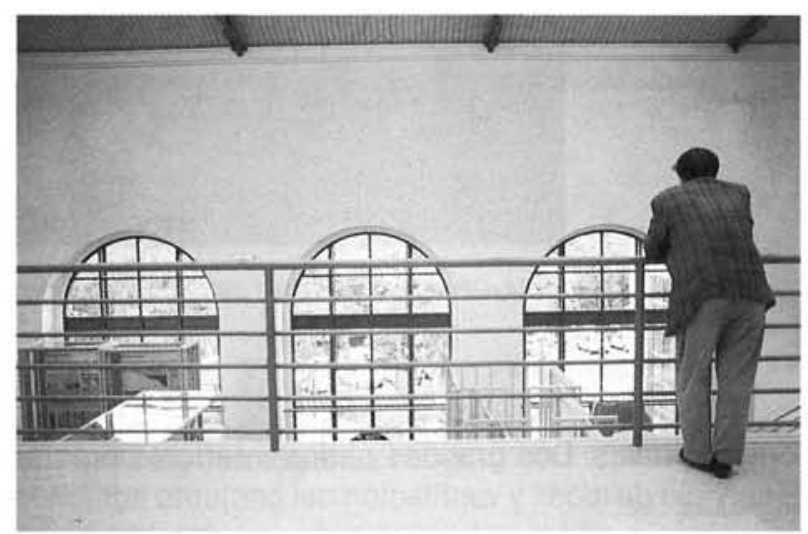

Fig. 12.-Con el tratamiento interior de las barandillas se ha intentado simplificar y aclarar el espacio interno permitiendo la visibilidad del entorno exterior.

Constituyen la estructura general del edificio siete grandes cuerpos:

El primero y más importante de éstos es el que ocupa el centro de la construcción y por su cabeza presenta el gran pórtico de acceso por el lado del Paseo de la Castellana; siguen en orden preferencial dos alas laterales que terminan el edificio al norte y al sur, hallándose enlazadas entre si por medio de cuatro galerias 

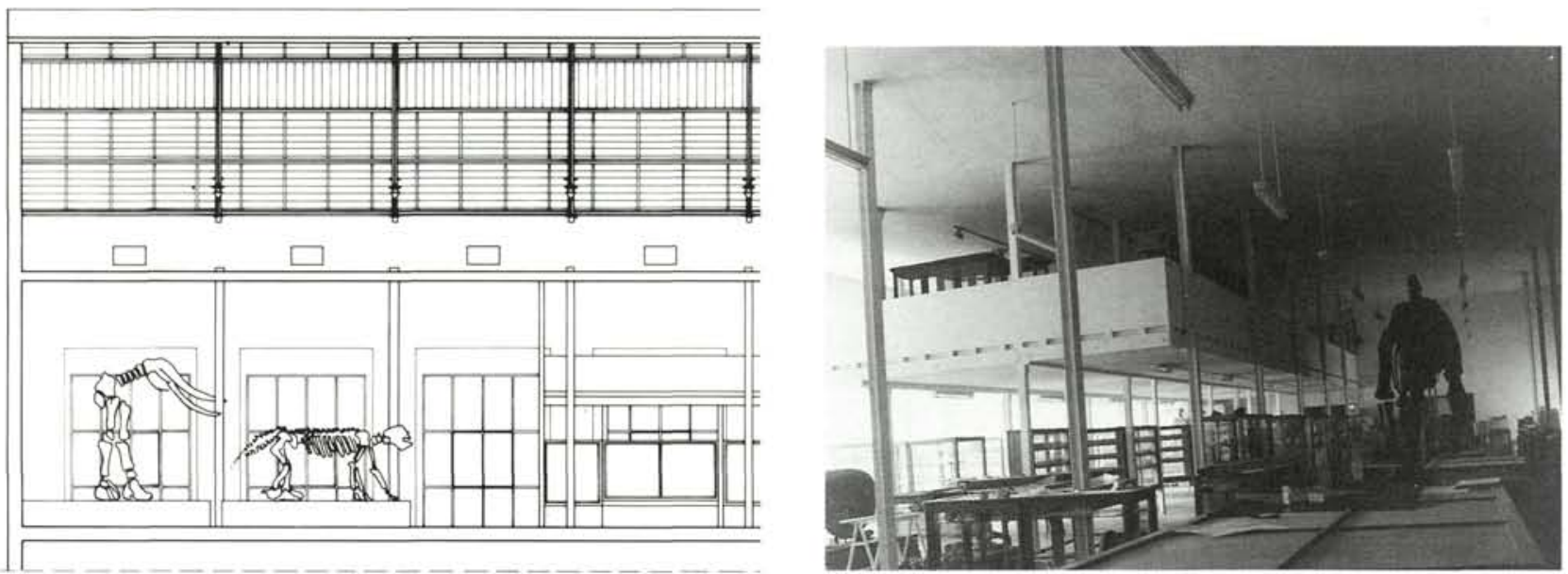

Fig. 13.-Perspectiva del estado primitivo.

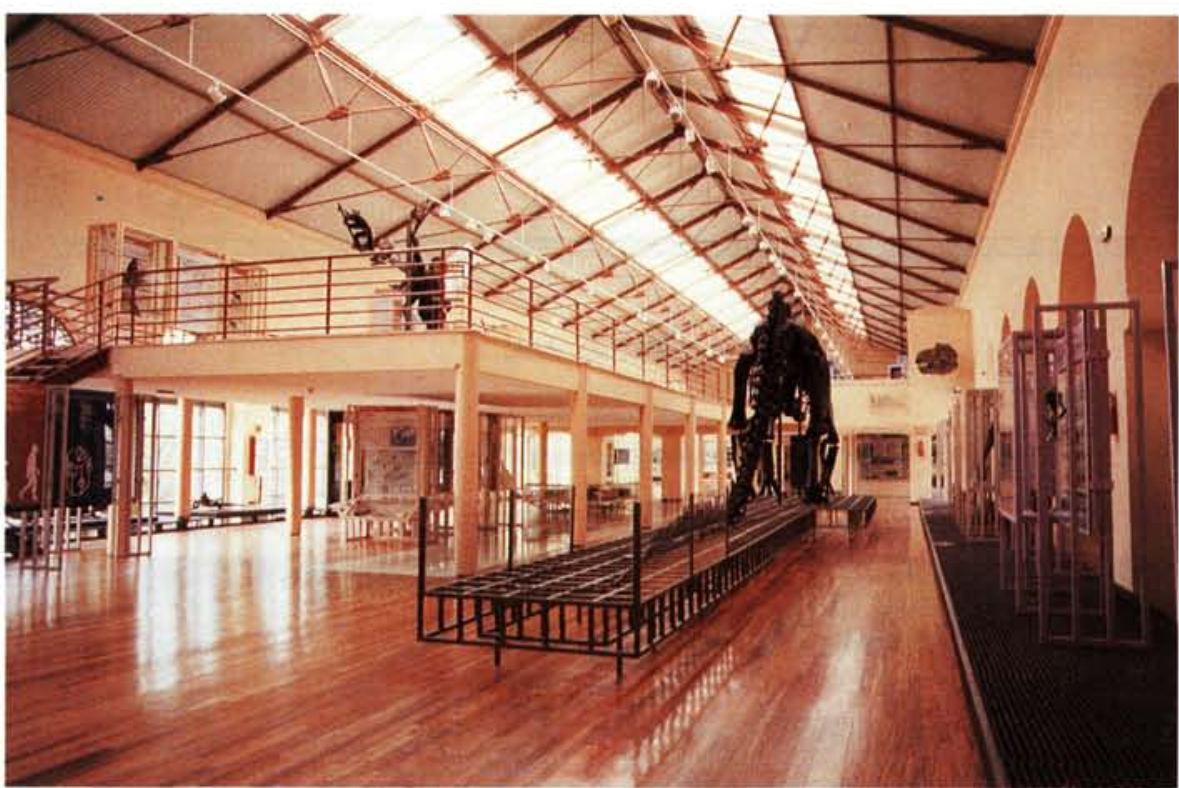

Flg. 14.-Perspectiva desde detrás del diplodocus, donde se observa el acondicionamiento realizado.

longitudinales. Dos grandes patios interiores prestan el servicio de luces y ventilación del conjunto edificado.

Este edificio, destinado en principio a ser sede de la exposición de la Industria y las Bellas Artes, sufrirá una transformación paulatina cambiando su función, para albergar las instalaciones del futuro Museo Nacional de Ciencias, cuya creación empieza a gestarse en octubre de 1771, al aceptarse el Gabinete de Historia Natural creado por don Pedro Franco Dávila en Paris, nombrándole director del mismo.

En 1774 se inaugura, en la calle de Alcalá de Madrid, el edificio de Bellas Artes, donde permanecerá el referido gabinete hasta 1895 .

(C) Consejo Superior de Investigaciones Científicas Licencia Creative Commons 3.0 España (by-nc)
En 1815 se le da el nombre de Real Museo de Ciencias Naturales.

En 1895 pasa a los bajos de la Biblioteca Nacional.

En 1906, el director del Museo solicita al Ministerio de Instrucción Pública el "salón alto del pabellón del norte del Palacio de la Industria y de las Artes" para instalar el laboratorio y colecciones de Entomología y la Sociedad Española de Historia Natural.

En el edificio se fueron instalando con el tiempo diversos organismos de actividades muy heterogéneas, que nunca llegaron a funcionar perfectamente al no estar el edificio pensado para albergar tal diversidad de es- 

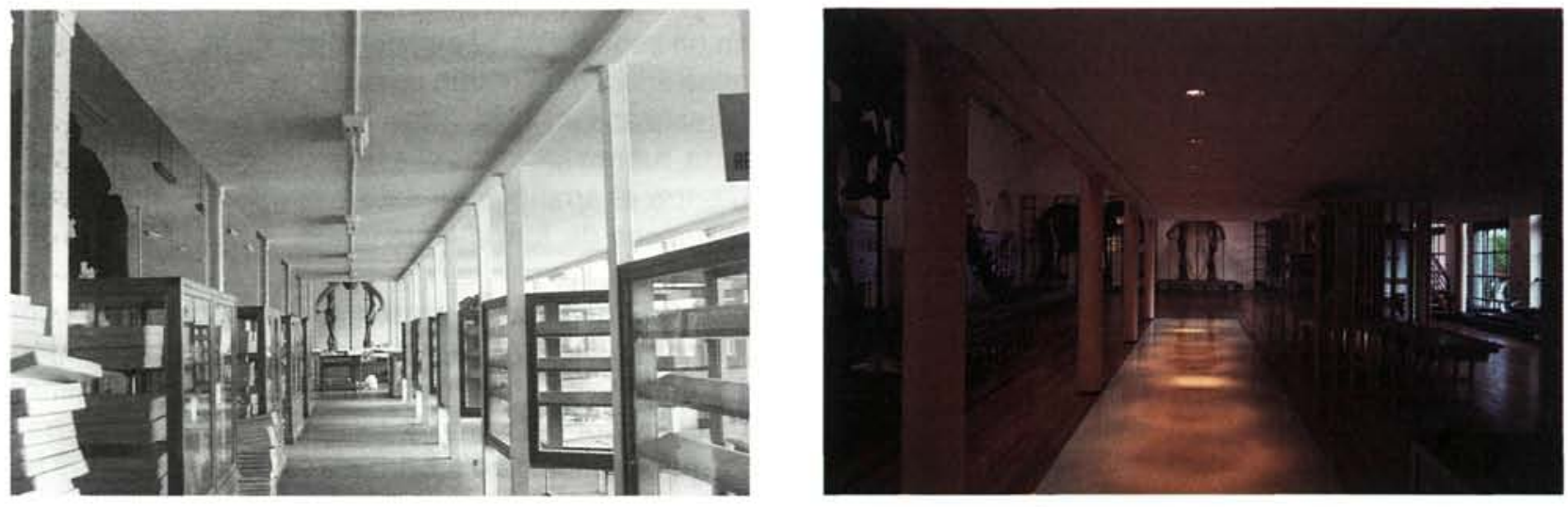

Figs. 15 y 16.-El bosque de columnas desaparece en el tratamiento del acondicionamiento y se señala con pavimentos e iluminación el eje longitudinal.

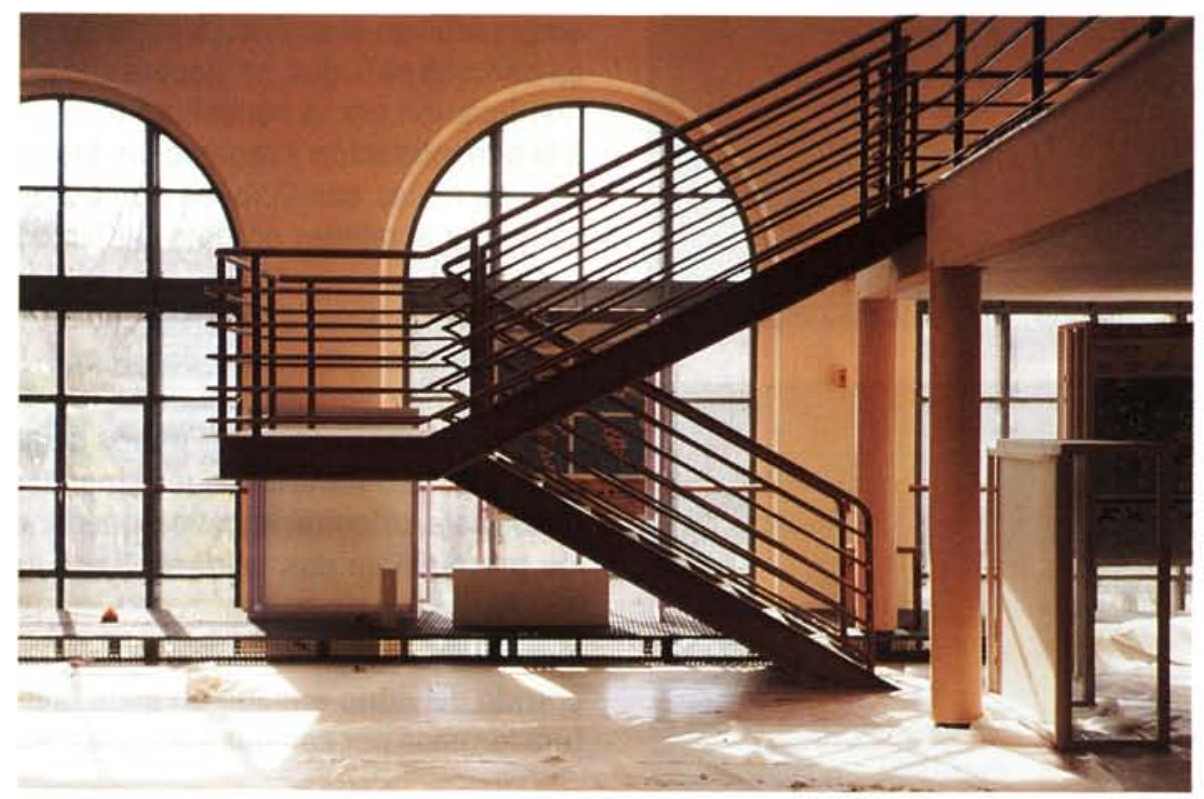

Fig. 17.-Escalera de acceso a entreplanta.

tamentos, como son la Escuela de Ingenieros Industriales, el laboratorio de Investigaciones Físicas, la Guardia Civil y el Museo del Traje.

El primer organismo en abandonar el edificio fue el Museo del Traje. Posteriormente, en 1930, la Guardia Civil empieza a desalojar el edificio. El laboratorio de investigaciones Físicas se trasladó al edificio destinado a albergar la Fundación Rockefeller.

El Museo de Ciencias irá ocupando los locales dejados por los anteriores organismos, quedando al final sólo el Museo y la Escuela de Ingenieros Industriales.

El Museo de Ciencias ocupa el Pabellón lateral norte, (c) Consejo Superior de Investigaciones Científicas Licencia Creative Commons 3.0 España (by-nc) donde está instalada la sala de Zoologia; el ala longitudinal derecha, orientada al Oeste mirando al Paseo de la Castellana, es donde se instalan las Salas de Mineralogia y Paleontologia; y en 1935 se construye el pabellón de Laboratorios y el ala longitudinal derecha situada detrás de la anterior, que es ocupada por despachos y servicios administrativos. El resto del edificio lo ocupa la escuela de Ingenieros Industriales.

\section{ESTADO DE LAS SALAS ANTES DE LA ACTUACION}

Nuestra intervención en el edificio se limita al ala longitudinal Oeste, que une el pabellón central con el pabellón lateral Sur, y que consta de planta baja de acceso, planta primera y entreplanta. 

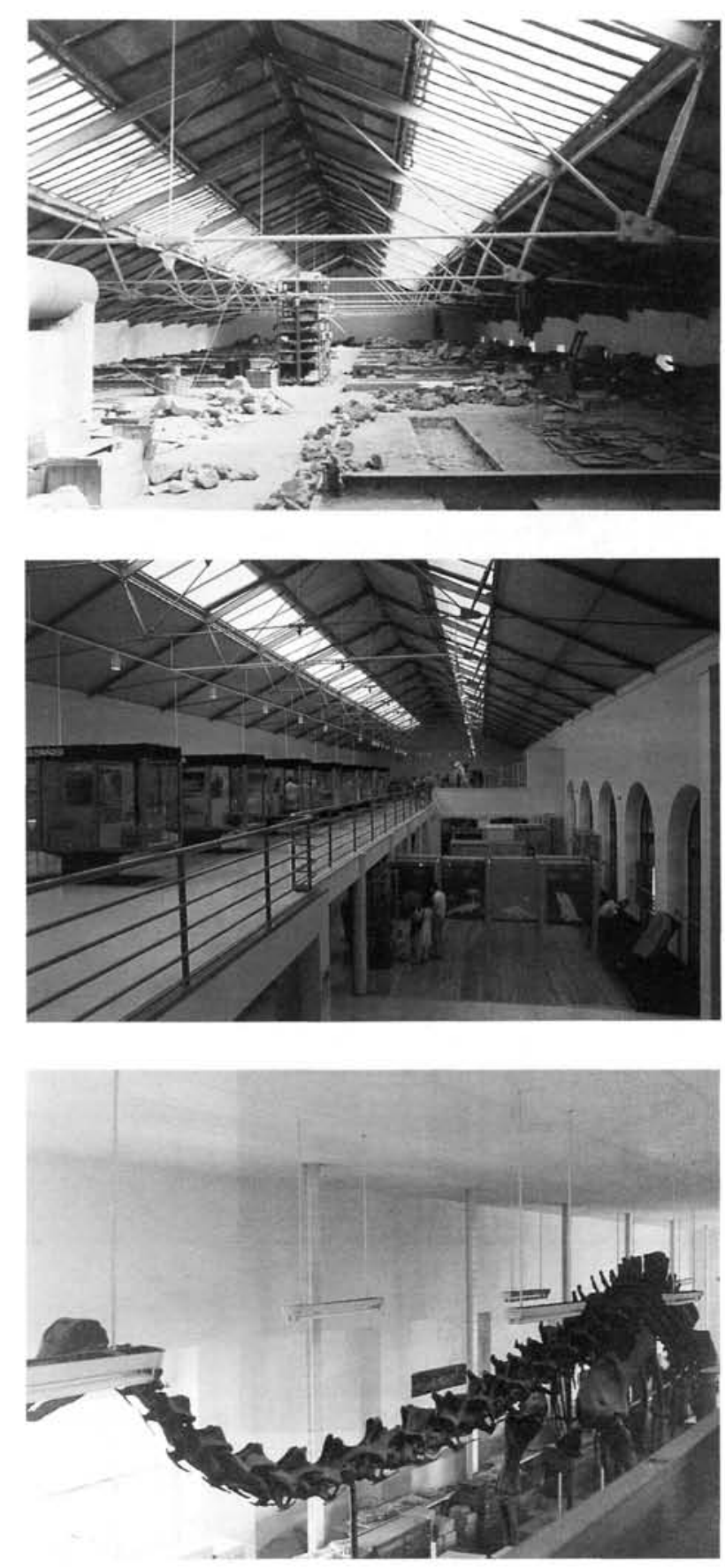

Fig. 18.-Aspecto del desván antes y después del acondicionamiento.

Inspirado el proyecto en las grandes construcciones de carácter industrial, realizadas en otros países para albergar este tipo de exposiciones, requerian de esbeltez y grandes luces. El material capaz de resolver estos problemas en aquella época era el hierro, que se convertiria en indispensable, durante el siglo XIX, en este tipo de edificios.

El Palacio de la Industria y de las Artes será el primer edificio en España, en donde en aquel momento se utiliza a gran escala un material innovador como es el hierro.
El ala longitudinal es un rectángulo de $55 \mathrm{~m} \times 17 \mathrm{~m}$ en forma de nave industrial.

Los muros de fachada están realizados con ladrillo macizo prensado a cara vista, fabricados en Valladolid; tienen un espesor de $72 \mathrm{~cm}$, con huecos de fachada acabados en arco de medio punto. Con motivo de la reforma realizada en 1930, para construir un desván en cubierta, fueron cerrados el espacio del arco comprendido entre el arranque de éste y el intradós, quedando los huecos de forma rectangular.

Los muros de fachada presentan un desplome de consideración hacia el interior, no siendo visible ningún otro sintoma patológico en la estructura, tanto exterior como interior del edificio, tales como grietas en muros, deformaciones o movimientos de la estructura interior.

Con motivo de las sucesivas obras de reforma que se emprenden en el edificio, a partir de 1930, escalonadas en diversos períodos, se ejecuta una primera parte, cuya justificación era la necesidad inmediata de proceder a la consolidación y reparación de elementos del edificio en malas condiciones con objeto de preparar el edificio y acometer el resto de las obras.

Las primeras obras de consolidación y reparación son encargadas al arquitecto don Modesto López Otero.

Debido al desplome de los muros de fachada, se construye un muro transversal intermedio de $30 \mathrm{~cm}$ de espesor, para arriostrar aquéllos, quedando dividido el salón principal en dos salones. (Ver Fig. 5).

La cubierta se realizó a dos aguas, con un lucernario corrido de vidrio armado en cada faldón y con estructura formada por cerchas metálicas del tipo Polonceau.

Destaquemos que la cúpula que remata el cuerpo central del edificio se fabricó en Bélgica, montándose posteriormente en España y la Empresa constructora que realizó el edificio era también del pais mencionado.

Las cerchas están enlazadas por correas y parecillos metálicos, sin protección antioxidante; sobre éstos descansa un enrrastrelado de madera de pino, formando un encasetonado que tiene por objeto recibir el entarimado de tabla machihembrada, sobre la que descansa la cubierta de teja plana sentada a torta y lomo siendo los canalones y bajantes de cinc.

En 1930, debido al mal estado de la cubierta, que provoca continuas filtraciones de agua que afectan a las fábricas de los muros, se desmantela ésta, se colocan nuevos canalones, se crean nuevas bajantes y se procede a retejar toda la cubierta. 


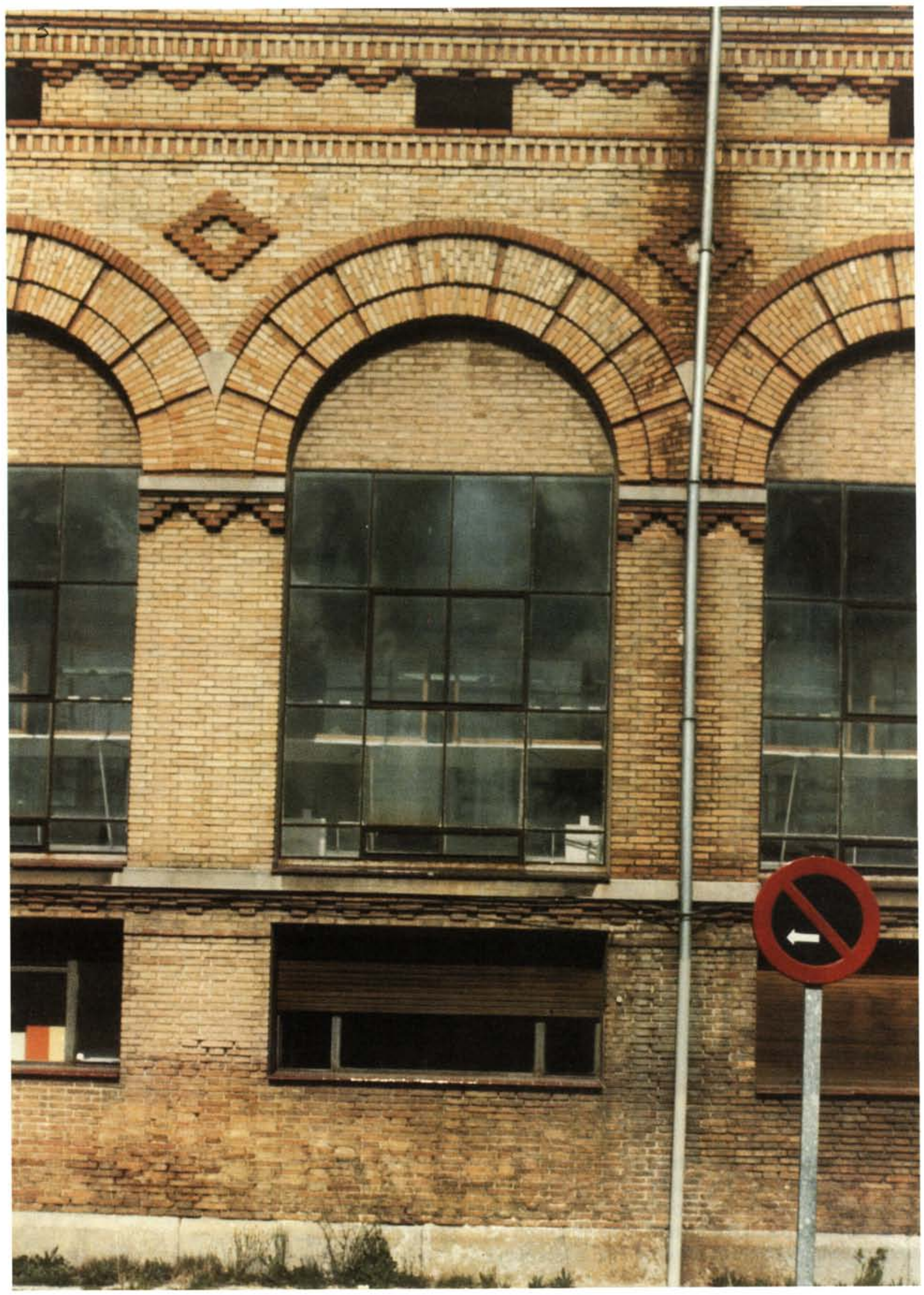

Fig. 19. - Alteraciones en la fachada (estado primitivo), donde figuran los huecos de ventilación del desván, el cerramiento del tímpano y los huecos de los laboratorios, asi como las humedades y deterioros producidos por la bajante. (Ver Fig. 20 del estado actual). 


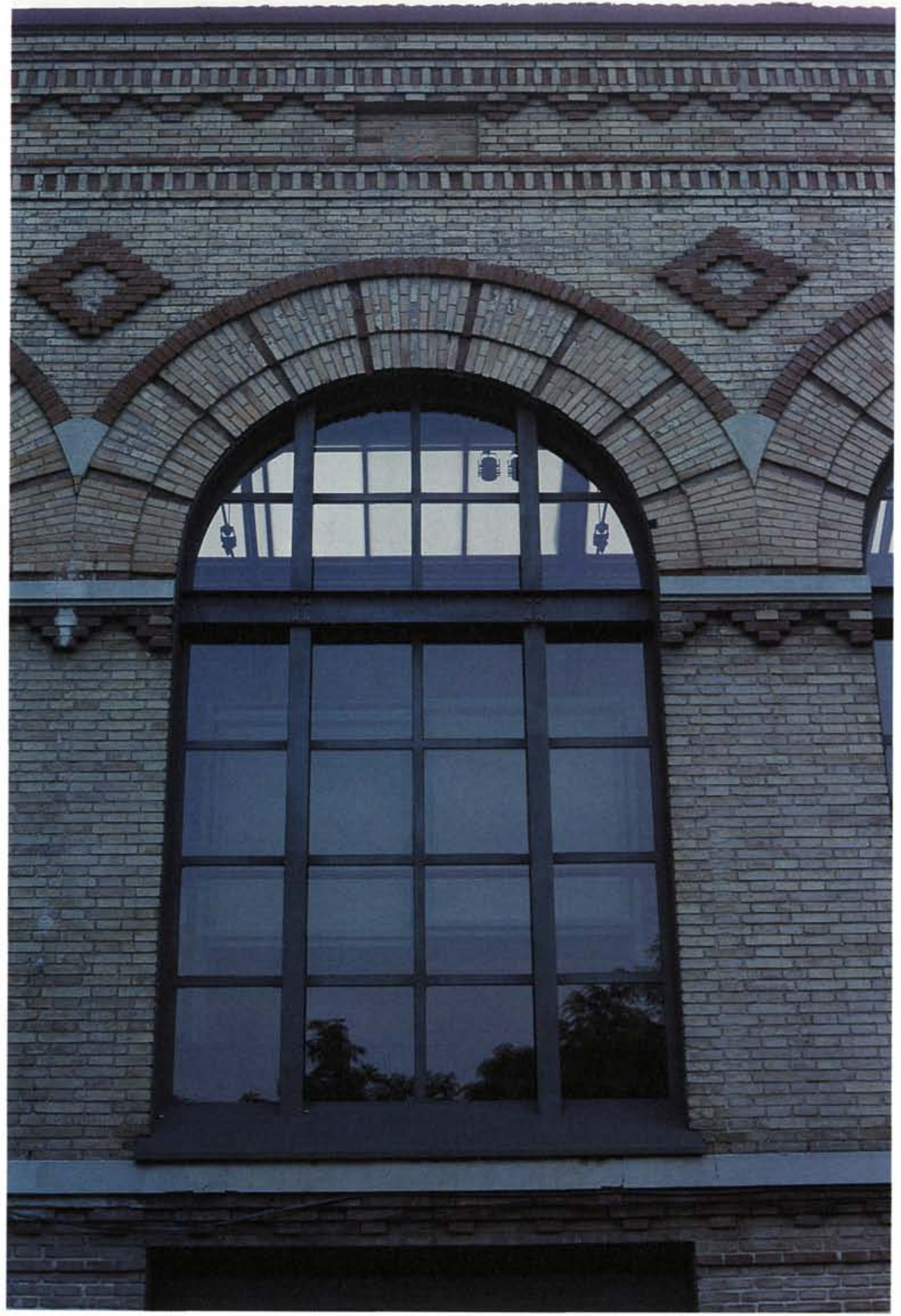

Fig. 20.-

Posteriormente la cubierta sufre otra reforma cuya fecha se desconoce, aunque puede establecerse entre los años 1940 y 1950, colocándose encima de la estructura de correas y parecillos un tablero de hormigón aligerado con viruta, sobre el que descansa la teja plana.

La carpinteria exterior es de hierro de $2 \mathrm{~cm}$ de sección, con un bastidor resuelto con despiece en cuarteles, dos

(C) Consejo Superior de Investigaciones Científicas Licencia Creative Commons 3.0 España (by-nc) de éstos abatibles en la parte central, y montante superior en forma de arco de medio punto, con varillas radiales y concéntricas que separan los cristales adyacentes. (Ver Fig. 19).

Los junquillos son de madera. El acristalamiento está formado por vidrio sencillo colocado con masilla. Por el interior, las ventanas van dotadas de tableros de mahttp://informesdelaconstruccion.revistas.csic.es 
dera con sistema de corredera que permite graduar la luz y sirven a la vez para el cierre total de los huecos.

Con motivo de la reforma de 1930 , se sustituye la carpintería de los huecos por otra también de hierro de la misma sección, sin montante superior y con despiece de cuarteles distinto.

Se desmontan los tableros de madera que gradúan la entrada de luz.

Inicialmente el espacio interior es una nave de una planta, pero entre 1930 y 1935 se levanta una estructura metálica de pilares y vigas de acero.

Don Modesto López Otero proyecta dos salas: la de Mineralogia y la de Paleontología, construidas entre 1930 y 1935.

Don Manuel Sánchez Arcas realiza el proyecto para la construcción del pabellón de Laboratorios y termina las dos plantas del vestíbulo de entrada.

Cada nueva sala consta de dos plantas: la primera inferior recibe luz lateral en las dos salas, y la superior en galeria recibe luz zenital.

Con motivo de la reforma de 1936, el suelo entarimado de la sala primitiva se sustituye por una losa de hormigón y pavimento con mosaico de Nolla, incluidos los rodapiés.

A principios del siglo $X X$ se conistruye un cielo raso de cañizo y casetones, que son demolidos en 1930 por el mal estado en que se encontraban. En su lugar se levanta una planta-desván en cubierta, con forjado de estructura metálica y doble tablero de rasilla, con claraboyas de vidrio moldeado permitiendo dejar pasar la luz, que entra por los lucernarios de cubierta, hasta las salas de las plantas inferior y superior. La cimentación del edificio es de piedra de pedernal.

El edificio dispone de calefacción por caldera de leña, con calderín de expansión situado en el desván, circuito bitubular de tuberia de acero y radiadores de fundición.

La iluminación artificial del edificio resulta precaria; $\sin$ embargo dispone de una iluminación natural importante, que penetra por los ventanales laterales y por los lucernarios de cubierta.

Actualmente las luminarias son regletas y pantallas colgadas con dos tubos fluorescentes cada una. No se ha tenido en cuenta, al iluminar, los objetos y vitrinas existentes.

(C) Consejo Superior de Investigaciones Científicas Licencia Creative Commons 3.0 España (by-nc)

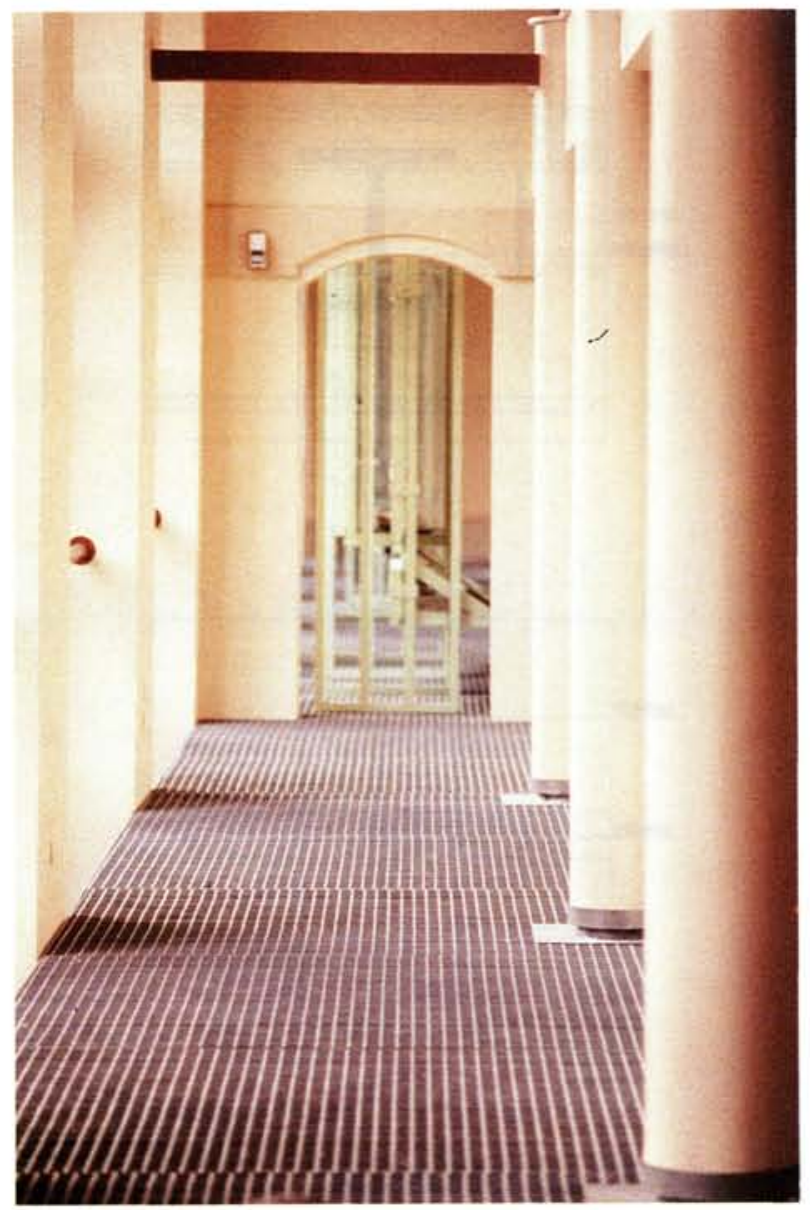

Fig. 21. - Paso lateral de rejilla como galeria de mantenimiento e ins. talaciones sobreelevada, a su vez, sobre el pavimento real.

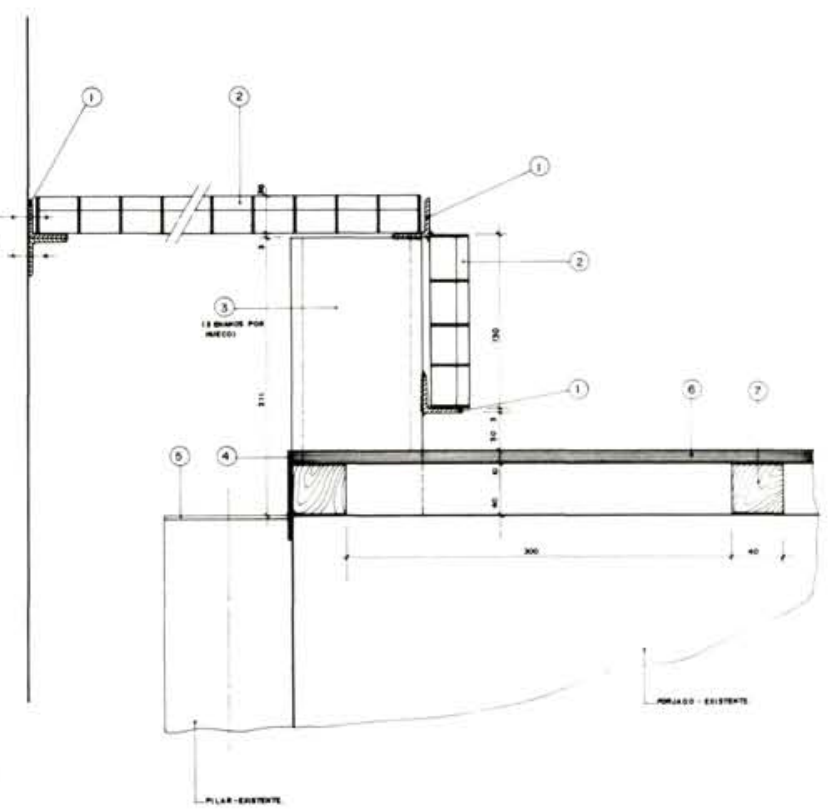

1.-Angular 30/30/3. 2. Rejilla electrosoldada (Malla MESH 30/30/2). 3.-Enano 2 [] PN - 100. 4.-Pletina de 70 22. 5.-Tapa pilar. 6.-Tarima de elondo. 7.-Rastrel.

Fig. 22.-Detalle entre muro y pavimento.

http://informesdelaconstruccion.revistas.csic.es 

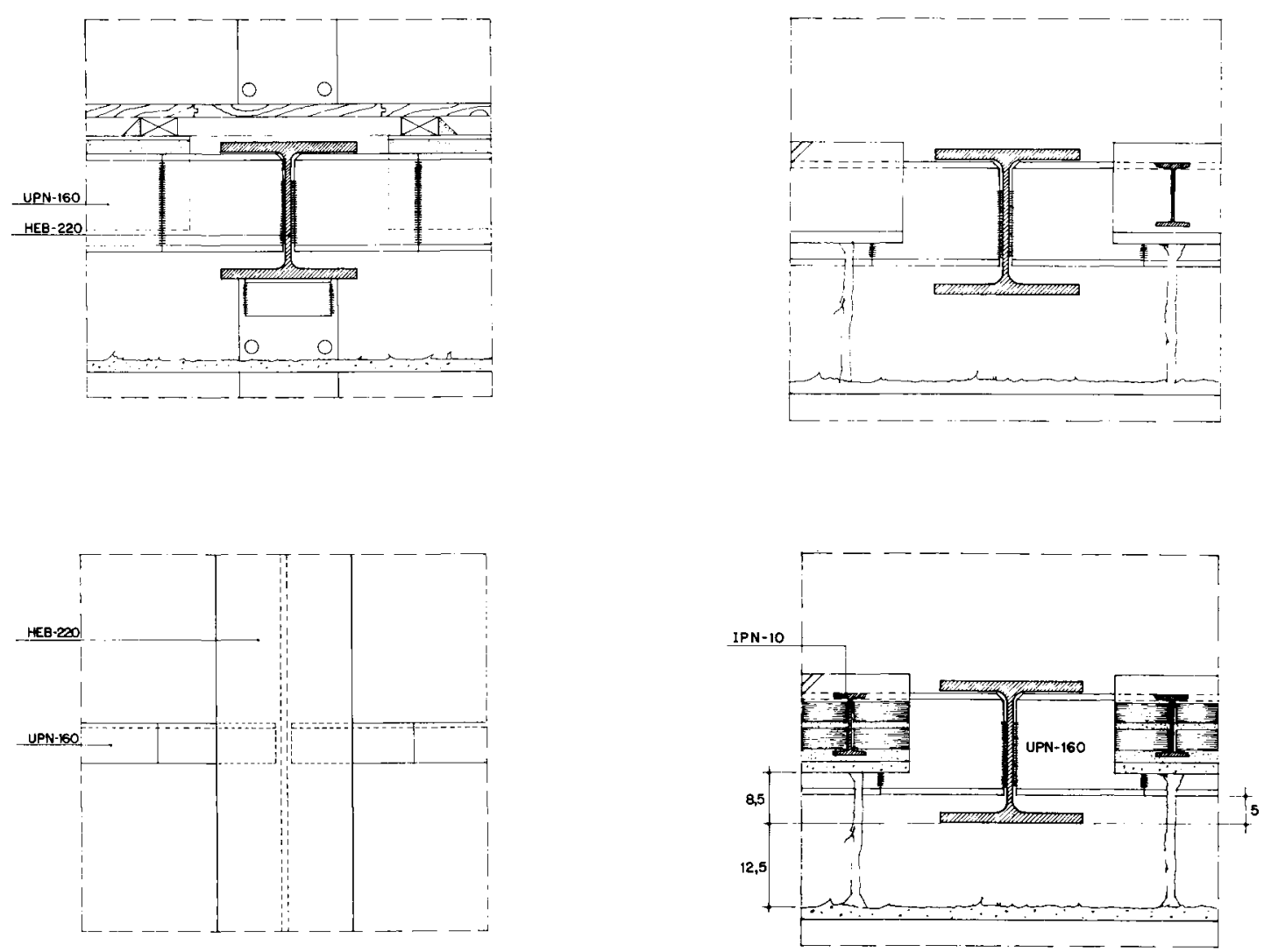

Fig. 23.-Viga de entreplanta.
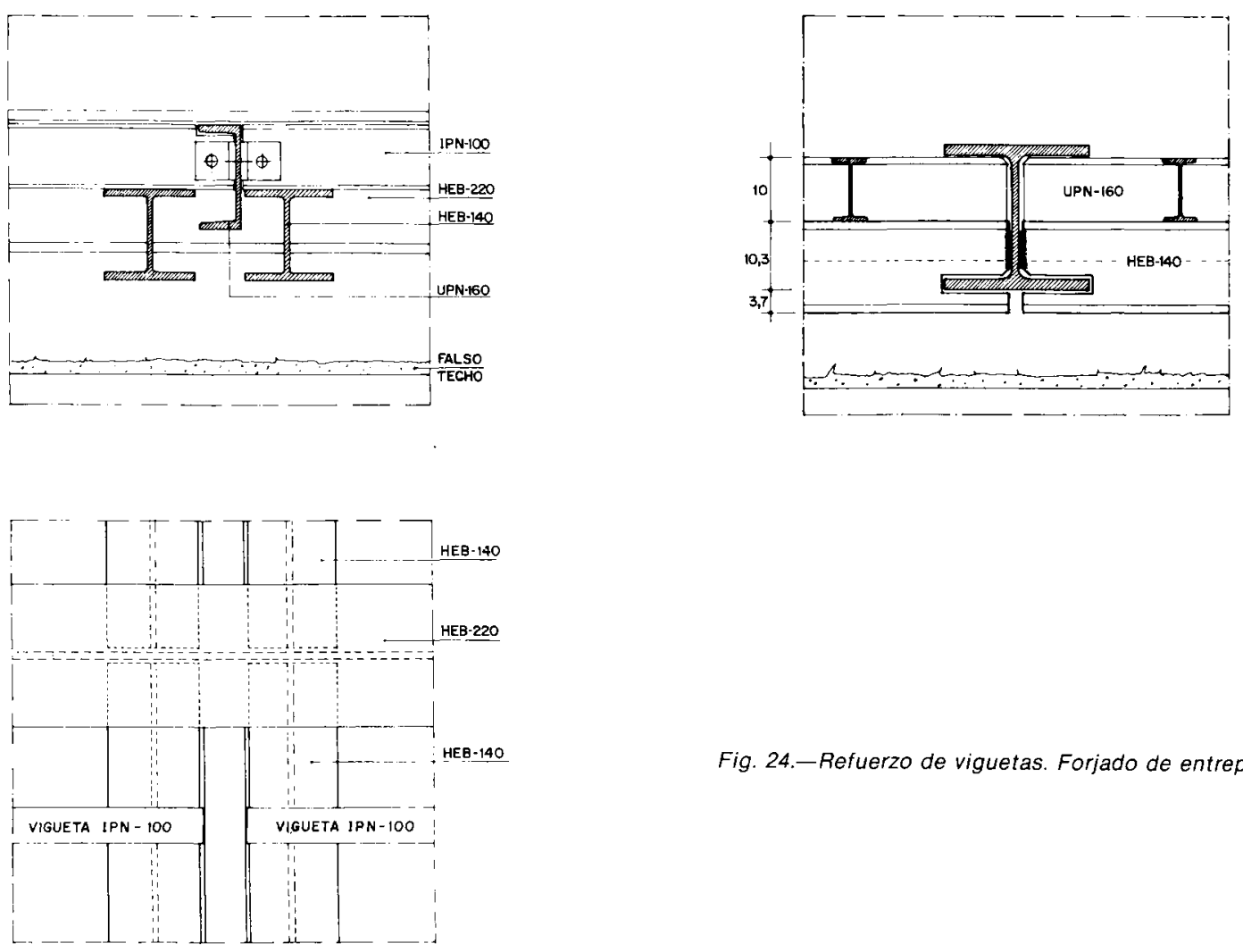

Fig. 24.-Refuerzo de viguetas. Forjado de entreplanta. 


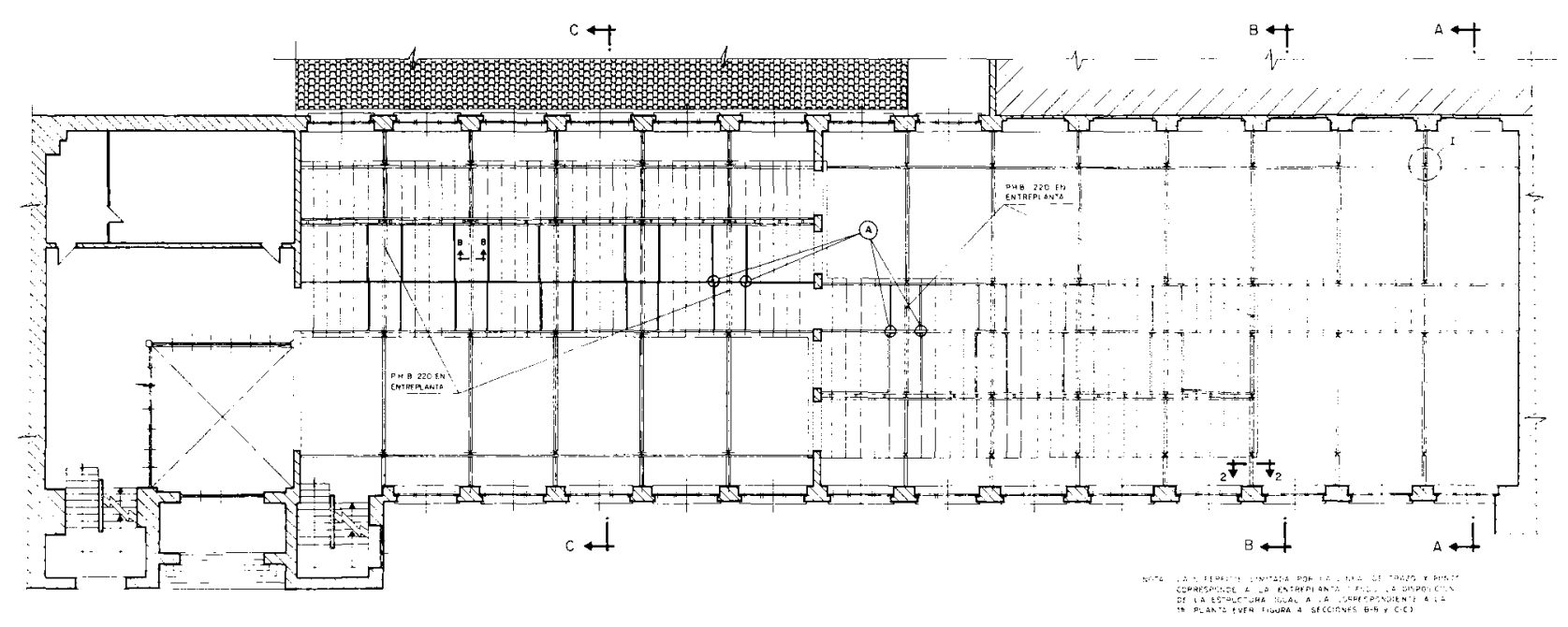

Fig. 25.-Estructura de la entreplanta.

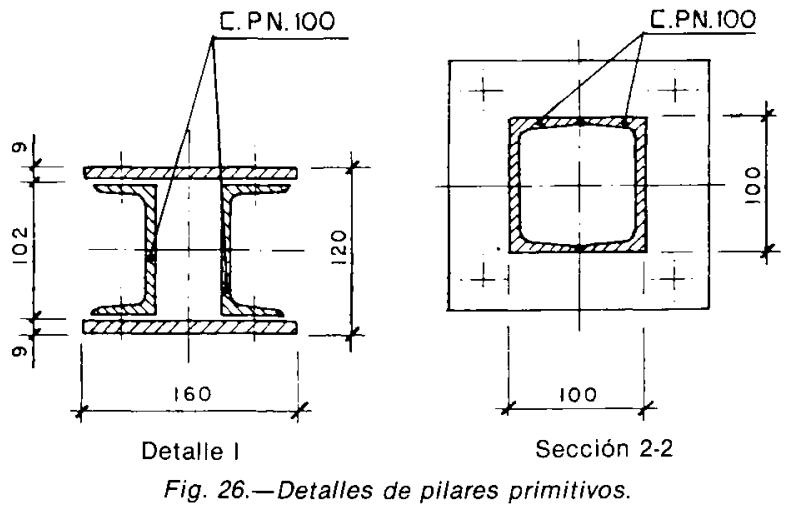

No existe aire acondicionado en las salas. Para ventilar el desván se abren huecos rectangulares en los muros de fachada; encima de cada uno de los ventanales de ésta, y para dar luz natural a los laboratorios de la planta baja, se abren ventanas apaisadas debajo de cada ventanal centradas respecto a éste.

Las sucesivas obras de reforma y consolidación, así como los diferentes organismos que han tenido y siguen teniendo su sede en el edificio, han desfigurado en gran medida el edificio proyectado en 1881.

\section{FILOSOFIAA DEL ACONDICIONAMIENTO}

Considerando las condiciones económicas en que se basaria el acondicionamiento, se comienza el trabajo con la idea de contenedor e intentando lograr una forma de exponer radicalmente opuesta a la existente hasta la fecha, la cual adolecía de acumulación de fósiles y ausencia de información, así como falta de intencionalidad didáctica, máxime cuando este Museo es el más visitado por colegios y niños. Esta última premisa aconseja lograr un espacio diáfano y, en lo posible, lúdico, que no prohiba, aunque controle, los múltiples movimientos de los adolescentes. Así se define, con ayuda de los Dres. del MNCN, los itinerarios principales y las piezas básicas a exponer, ejecutándose co- mo consecuencia un modelo de vitrina de múltiple uso que, por problemas de contratación del CSIC, no llega a ejecutarse, contratándose a equipos ajenos del redactor el tema de Museologia correspondiente, y variando en su concepto la forma de exponer que se consideró en la idea global.

Como consecuencia directa, de este hecho surge la primera idea indicada: la de nave abierta sin obstáculo alguno para que sea posible cualquier hecho expositivo.

Los cambios de dirección en el Museo asi lo aconsejan, ya que se desconoce en algunos aspectos el fin real de las salas, quedando únicamente claro que existen algunos fósiles, la reproducción del diplodocus, el elefante, megaterio y gliptodonte, los cuales deben ser restaurados y seguir ocupando sus respectivos lugares.

Esto supone otro de los condicionamientos importantes, pues es obligado desechar la posibilidad de realización de una galería perimetral concordante con el proyecto inicial de Fernando de la Torriente, y que hubiera simplificado radicalmente el contenedor.

La falta de fondos, junto con la dificultad de movimiento del diplodocus, y la fragilidad del elefante, prohibe desarrollar esta idea. Incluso se asume el riesgo de mover el megaterio, desplazándolo hacia el fondo de la sala, con el fin de centralizar en volumen los grandes fósiles de mamiferos, eliminándose las formas de sujeción y apoyo que tenian por otras más ligeras y que colaborarán con la impresión de amplitud que se inten: taba lograr. (Ver Fig. 31).

Se analizan los ejes del edificio que, en este ala, al igual que todos los pabellones laterales del conjunto, posee dos ejes fundamentales: uno longitudinal coincidente con la cumbrera de la cercha, otro donde se desarroIlan los acontecimientos museísticos y otro transversal, marcado por la cancela de acceso y vestíbulo en- 


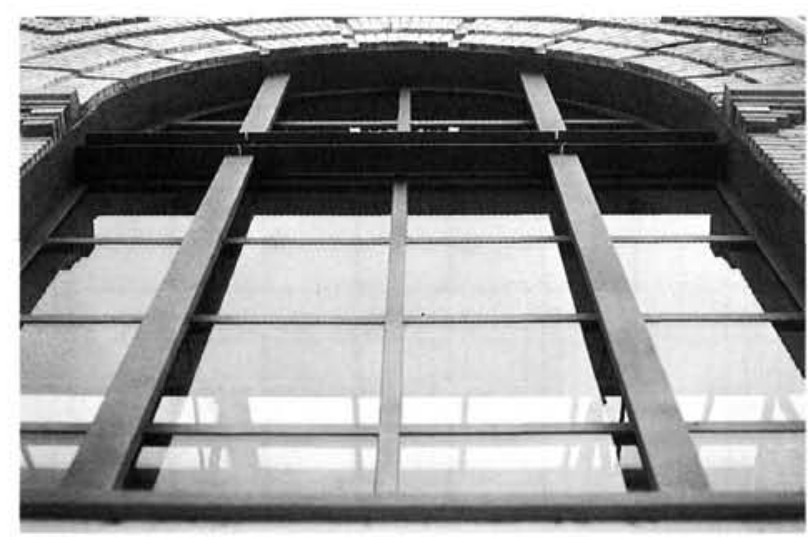

Fig. 27.-Perspectiva de la nueva carpinteria.

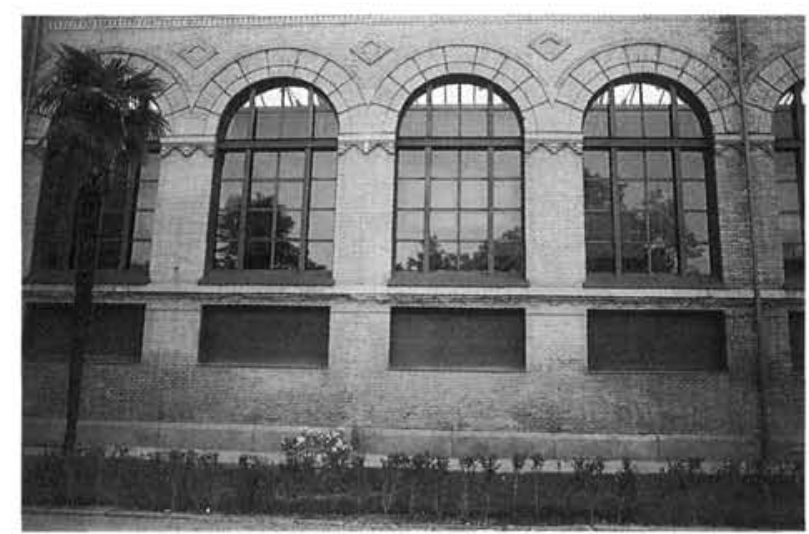

Fig. 28.-Detalle de fachada de la Sala de Paleontologia y Mineralogía después de la reforma.

Actuación en la fachada del edificio con el tratamiento de huecos, bajantes, alféizares y marquesina simple de la misma. tre los torreones de movimiento vertical y que termina en el patio interior, desarrollándose en él la zona ac servicios del Museo.

La actuación en este eje ha sido siempre problemática, e incluso hubo que desechar convertirlo en parte para mejora del acceso al sótano y hueco del ascensor por problemas del Departamento de Personal, obligando a trasladar este ascensor al único sitio con posibilidad real de colocación.

Estos ejes conducen a clarificar otra de las premisas del proyecto, acentuando y marcando éstos, no sólo a nivel de pavimento con el levantamiento lateral formando una zona de circulación y servicios, sino también con el descubrimiento de las cerchas originales ocultadas por un forjado, cumpliéndose asi una de las condiciones de la Memoria del Anteproyecto para el Palacio Regional de la Industria y de las Artes.

Las construcciones de hierro, que "tan inmensas ventajas proporcionan sobre los otros materiales", adoptan dos "estructuras inspiradas en el mismo criterio pero de formas esencialmente distintas, consistentes en la formación de tramos constituidos por pilastrones que limitan dos columnas separadas entre si por cajones de fábrica de ladrillo prensado y que comprende el vano de luz cerrado en forma curva o de medio punto".

El eje transversal deberá con el tiempo tratarse, pero esperando siempre el desalojo de los I. Industriales, pues ahora lo ocupa la chimenea de una fundición y un buen edificio racionalista de Sánchez Arcas, aunque mal situado, ocupado por los laboratorios de $\mathrm{Pa}$ leontología. La limpieza de este espacio ayudará a redescubrir el edificio. Sin duda.

Surge asi el contenedor final, que todavía se ve afectado por dos elementos: la fachada y el color.
Tras un análisis profundo de la fachada, y croquizar todos los huecos existentes en el edificio, incluyendo I. Industriales, observamos que el tratamiento primitivo del edificio consideraba el hueco como un elemento más del despiece de la fábrica de ladrillo realizada, creando una malla cuyo aspecto fundamental es la falta de penetrabilidad que presenta, de tal forma que llega a mimetizarse con el despiece de la fábrica de ladrillo.

Esta carpinteria formada por 55 cuarteles, y siguiendo el despiece la forma del arco de medio punto, causaba el impacto descrito anteriormente. Aunque se pensó en este despiece, fue desechado por considerar una respuesta excesivamente literal al problema presentado, máxime cuando su aplicación se realiza en un hueco con arco carpanel, como existe en la fachada NE del edificio, y también por el problema técnico que supone un despiece tan enorme en el vidrio climalit, adquiriendo entonces la carpintería un protagonismo tal que desequilibraria el hueco que se pretendiera colocar.

Por ello se ha estudiado una carpinteria que, ajustándose a cualquier tipo de arco (carpanel, y medio punto) y hueco, respondiera a la filosofia indicada en el primer párrafo, es decir, causara impacto de impenetrabilidad y fuera a su vez consecuencia directa del despiece de fachada. (Ver. Fig. 29).

Se realizó con perfiles tubulares de acero, con tratamiento antioxidante y pintados. Los vierteaguas también se realizaron en acero.

No se coloca cierre alguno suplementario, pues fue idea de la Dirección y compartida por nosotros, que la naturaleza exterior de la colina pudiera observarse claramente y participara como un elemento más en el hecho expositivo.

Por último aparece un elemento comentado ya anteriormente que influye en el acondicionamiento; el color. http://informesdelaconstruccion.revistas.csic.es 

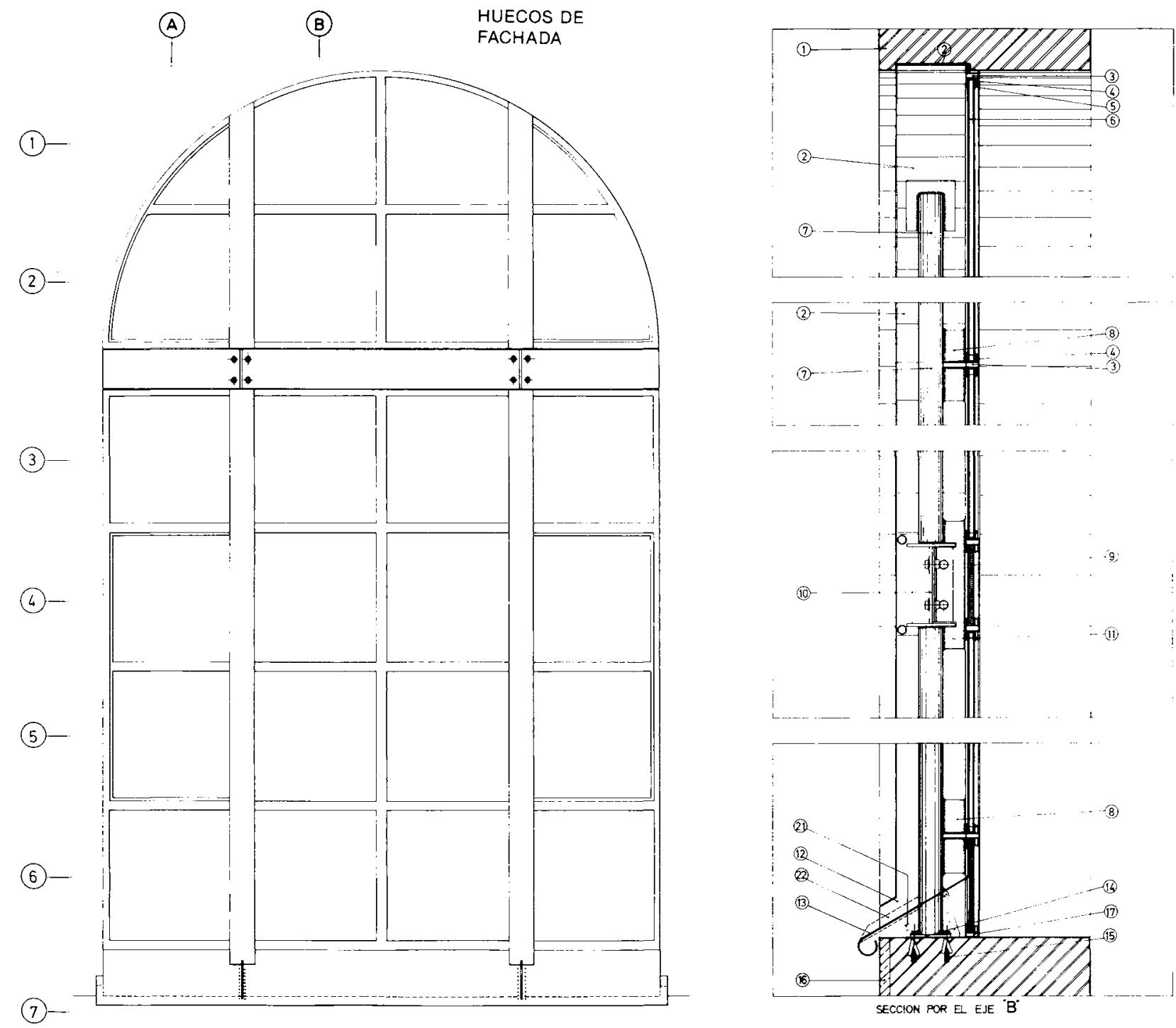

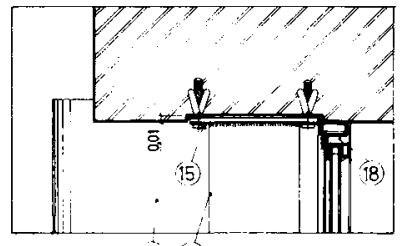

(13) (10)

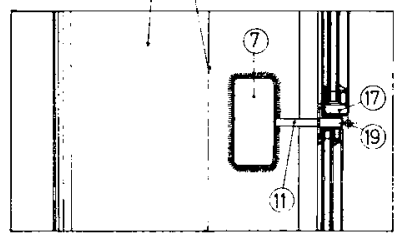

SECCION POR $6^{\circ}$

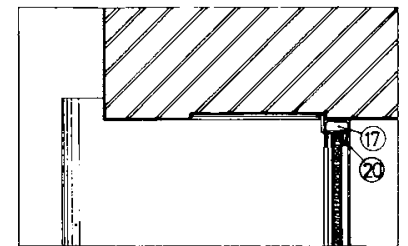
(13)

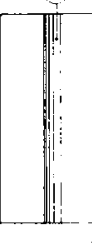

15) (7) (14

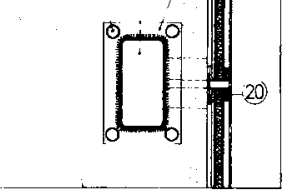

SECCION POR ${ }^{\circ 6}-7^{\circ}$
1.-Fábrica de ladrillo (primitiva). 2.-Recrecido de revoco de cemento. 3.-Perfil de carpinteria "Perfrisa" Serie B.5479. 4.-Junquillo "Perfrisa" R.5518. 5.-Galce de neopreno. 6.-Doble acristalamiento "climalit" $4+6+4$. 7.-Parteluz: tubo estructural de $80 \times 40 \times 2$. 8. - Pieza de fijación de la reticula de carpintería al bastidor exterior. 9.-Chapa $\neq 0,5 \mathrm{~mm}+$ polydros e: $15 \mathrm{~mm}+$ chapa $\neq 0,5 \mathrm{~mm}$. 10.-Doble T de palastro $\neq 10 \mathrm{~mm}$ de $200 \times 120$. 11.-Pieza de fijación de la reticula de carpintería al bastidor. 12.-Canal lateral evacuación del alféizar 13.-Alféizar de chapa $\neq 2 \mathrm{~mm}$ miniada y pintada. 14.- Placa de asiento de los parteluces. 15.-Anclaje. 16.-Imposta de piedra artificial (primitiva). 17.--Perfil de carpinteria "Perfrisa" B.5479.
Este Museo recibe un gran número de visitantes en edad escolar, hecho que obligó a los museólogos a estudiar una forma de exposición orientada a ellos. Utilizaron, para identificar las distintas áreas, colores dife- rentes, todos ellos frios, y no sólo puntualmente, sino también en las vitrinas y otras masas más importantes, por lo cual el resultado final podría parecer desapacible. 
Debido a haber decidido que la base de las grandes piezas, las sombras de los mamíferos, la galería elevada de rejilla y las ventanas fueran en oxidón (tono gris logrado con negro y rebajado con ocre - mezcla acromática en el campo del naranja-), nos planteamos la conveniencia de variar la masa importante de los paramentos, cerchas y barandillas con un tono caliente que, a la vez, en su composición se pudiera considerar neutro, ayudando a matizar los múltiples tonos fríos de la exposición y formara un conjunto que tranquilizara al observarlo, usando para ello los equivalente al Pantone $475 \mathrm{U}$ como base. Por supuesto los matices están basados en que su observación es en base a la luz normalizada D65 equiparable a la luz del día, siendo mezclas cromáticas con amarillo en composición de tres colores.

\section{EJECUCIÓN DE LA IDEA}

Para lograr nuestro objetivo de recuperar el espacio - tal como fue concebido por don Fernando de la Torriente - como nave industrial diáfana, se nos plantea la necesidad de demoler parte del muro transversal levantado en 1930 por don Modesto López Otero, que teóricamente tiene como finalidad arrostrar los muros de la fachada debido al fuerte desplome que presentan éstos hacia el interior. (Ver Figs. 7 y 10).

Realizamos un estudio a pie de obra de la estructura metálica, levantada con motivo de la construcción del desván, para analizar si de alguna forma contribuye a arriostrar las fachadas. De ese estudio llegamos a la conclusión de que no desempeña ningún papel de arriostramiento, al no apreciarse deformaciones o movimientos que haya podido sufrir en el pasado.

Por otra parte, en fachada no existe ningún tipo de grietas, deformaciones o movimientos en la estructura metálica interior a pilares y vigas de los distintos forjados de las plantas -incluidas las cerchas de cubierta que apoyan en los muros de fachada - que delaten ningún movimiento de la fachada por desplome hacia el interior.

Es de destacar que el desplome no es en toda la altura de la fachada. Comienza por encima de la línea de im. posta, que pasa por debajo de los ventanales. El hecho de que la fachada esté realizada en ladrillo visto con un variado aparejo, con entrantes y salientes, definiendo una rica decoración de grecas, roscas de dis. tinto radio en los huecos de ventana, jugando con líneas de ladrillos volando unos sobre otros en cornisas y la relativa rapidez con que fue construido el edificio, nos hace pensar que el desplome pueda ser organiza- do en la propia fase de construcción del mismo, como resultado de una deficiente ejecución de los muros y no producido a posteriori.

A consecuencia de que los muros tienen un espesor de $72 \mathrm{~cm}$ y que el desplome en el punto más desfavorable es de $11 \mathrm{~cm}$, consideramos que de un primer análisis el desplome sólo no es suficiente para poner en peligro la estabilidad del muro.

No obstante, era necesario garantizar la estabilidad de los muros de fachada. Para ello contamos con la colaboración de dos técnicos de lberduero, S. A., que realizaron un estudio estructural del conjunto del edificio, analizando si la acción del viento puede someter a los muros de fachada a unos momentos que son de mayor importancia que el desplome.

El ala longitudinal del edificio, objeto de nuestra actuación, tiene una longitud de $55 \mathrm{~m}$ y una anchura de $17 \mathrm{~m}$; la altura sobre el nivel de la calle es de $11 \mathrm{~m}$. El muro posterior da a un patio situado $4 \mathrm{~m}$ por debajo del nivel de la calle.

La conjunción de ambos efectos, desplome y acción del viento, aconseja un estudio de la estabilidad; para ello debe incluirse la contribución de la estructura metálica interior y las cerchas de cubierta que apoyan y conectan con los muros.

Del estudio documental existente del edificio, firmado por don Modesto López Otero en septiembre de 1930, donde describe unas obras que no se corresponden con lo realmente llevado a cabo, se habla de realizar un recalce puntual del muro de fachada, motivado al parecer por unas fugas de agua de la red de saneamiento, pero no existe constancia de que la obra se llevara a cabo realmente; el resto de las memorias y planos arquitectónicos no tienen valor desde el punto de vista estructural.

Se realizaron catas en el encuentro de viguetas de forjado del desván que apoyan directamente en los muros de fachada.

Se realizó una medición de los desplomes mediante la tirada de plomadas desde la parte superior de los muros hasta el nivel situado a la cota $3,65 \mathrm{~m}$, que es a partir de la que se observa el comienzo del desplome.

Se estudiaron tres secciones transversales del edificio que se corresponden con las tres disposiciones existentes de la estructura interior. (Ver Fig. 25).

Para la realización de los cálculos se ha empleado el programa SAPID de elementos finitos, elástico y lineal, desarrollado por IBERDUERO, S. A., y basado en el SAP IV de la Universidad de Berkeley. 

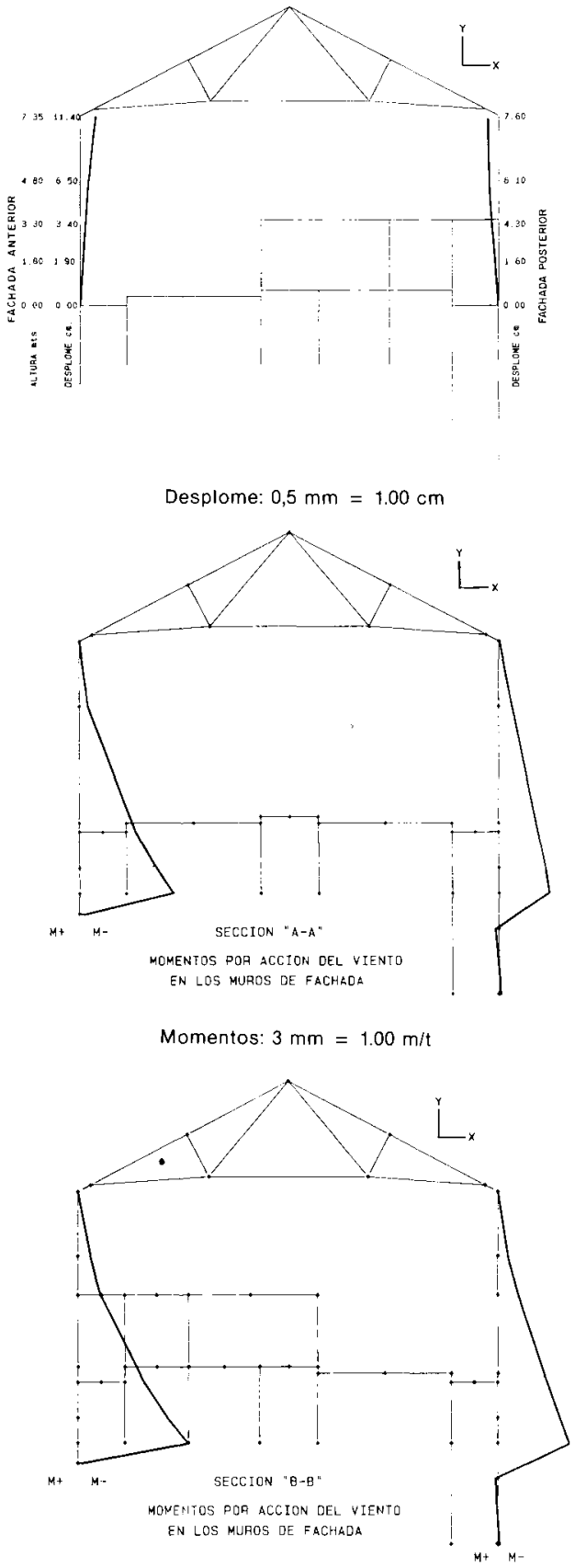

Momentos: $3 \mathrm{~mm}=1.00 \mathrm{~m} / \mathrm{t}$

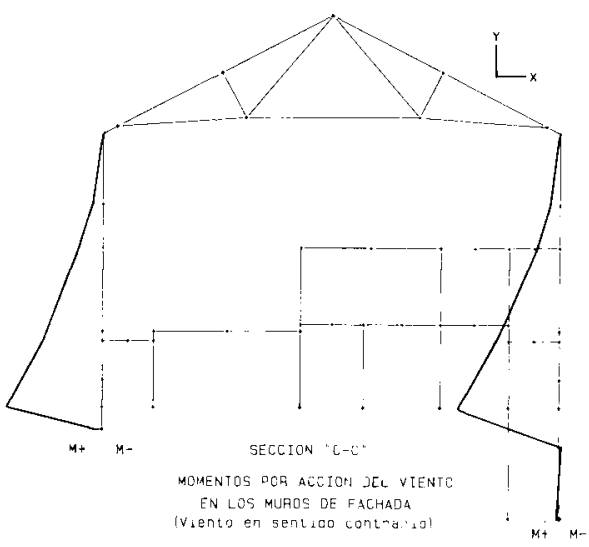

Momentos: $3 \mathrm{~mm}=1.00 \mathrm{~m} / \mathrm{t}$

Fig. 30
Tanto los muros de fachada como las cerchas y la estructura interior se han modelizado mediante elementos BEAM, asignando a cada uno de ellos las características geométricas y resistentes correspondientes.

Los desplomes de los muros se han tenido en cuenta mediante la corrección de las coordenadas de los nudos según las mediciones efectuadas, asignando a cada sección estudiada los mayores desplomes medidos en cada zona. Como hipótesis de cálculo, para determinar los esfuerzos, se ha supuesto un comportamiento de la estructura elástico y lineal.

Tanto los muros de fachada como los pilares de la estructura interior se suponen empotrados en el nivel inferior correspondiente.

Las cerchas de cubierta se suponen apoyadas en el eje de los muros de fachada no transmitiendo a éstos movimientos, pero sí fuerzas verticales y horizontales.

Las cargas consideradas han sido peso propio, sobrecargas permanentes, sobrecargas variables y carga de viento con presión normal de $50 \mathrm{~kg} / \mathrm{m}^{2}$ sobre fachada y $11,3 \mathrm{~kg} / \mathrm{m}^{2}$ sobre cubierta en el lado de barlovento, y una succión normal de $25 \mathrm{~kg} / \mathrm{m}^{2}$ sobre fachada y de $31,4 \mathrm{~kg} / \mathrm{m}^{2}$ sobre cubierta en el lado de sotavento.

Del análisis de los resultados se deduce que: El hecho de duplicar el valor del módulo elástico de los muros de fachada pasando de $80.000 \mathrm{~kg} / \mathrm{cm}^{2}$ a $160.000 \mathrm{~kg} / \mathrm{cm}^{2}$ supone una variación pequeña en los valores de los esfuerzos resultantes; para el caso de empuje del viento dicha variación es del 3 por ciento.

Las cargas a que la acción del viento somete a la estructura interior son muy pequeñas. Los esfuerzos sobre las cerchas si son de alguna entidad, pero o bien son de signo contrario a los producidos por el peso de la cubierta, o en el caso de ser del mismo signo no tienen magnitud suficiente para alterar sustancialmente el funcionamiento de la cercha.

Los momentos producidos en los muros, para alcanzar valores de cierta consideración, exigian un estudio tensional de las secciones críticas, el cual se llevó a cabo.

Las conclusiones resultantes del estudio fueron que el muro macizo de $30 \mathrm{~cm}$ de espesor que separa las salas de mineralogia y paleontologia, aunque a nivel de la primera planta, es demasiado, se mantiene en planta baja, por lo que el efecto estabilizador sobre los muros de fachadas debe ser importante. (Fig. 30).

El techo de las dos salas, que oculta la estructura de cerchas de la cubierta, es demolido dejando visto el interior de la cubierta. 


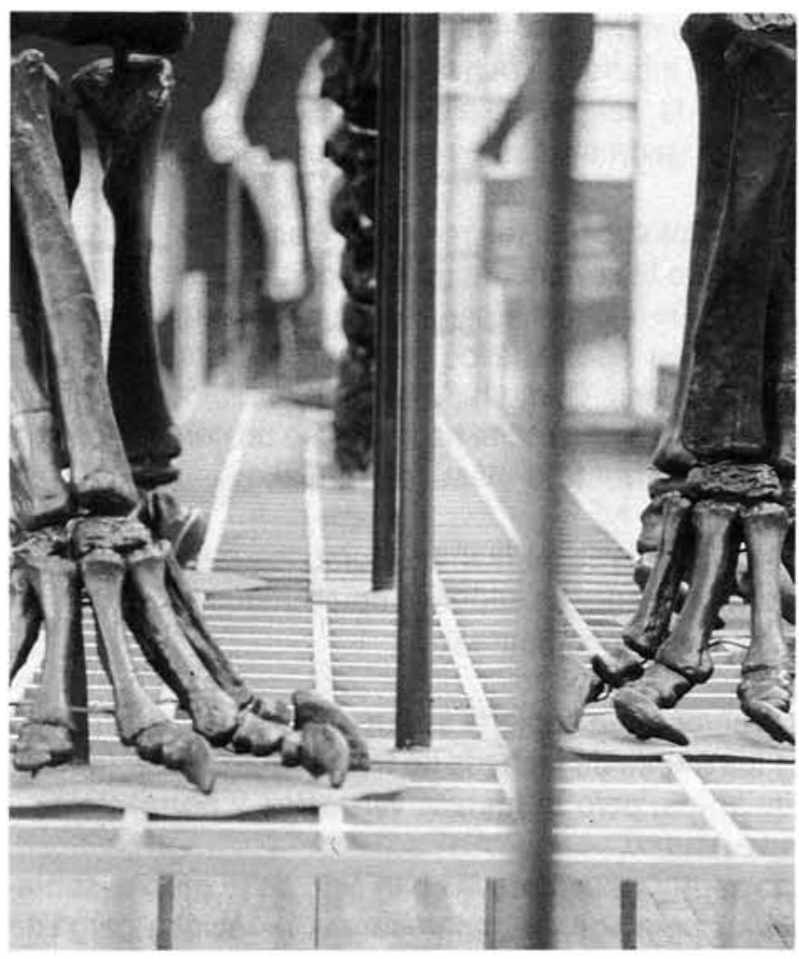

Fig. 31.-Base de apoyo de los grandes fósiles de mamiferos qu ali gera el espacio al eliminar la base anterior de madera, destrozada és. ta por los grafitis.
Se remata la cubierta por el interior con chapa de perfil nervado de aluminio lacado, recibida sobre una estructura auxiliar, colocando un aislante térmico en la cámara de aire que se forma entre la chapa y el tablero de hormigón aligerado. Los lucernarios de cubierta se desmontan totalmente y se diseña uno nuevo, realizado con estructura de aluminio lacado y planchas celulares de polimetacrilato de metilo de $16 \mathrm{~mm}$ de espesor. Se elige el color blanco opal, por ser el que más reduce la penetración de luz natural, ya que consideramos que con el anterior lucernario existia un exceso de luz cenital, perjudicial para una correcta visión de los distintos objetos existentes en las salas.

Consideramos que el riesgo de condensaciones en el interior de la cubierta se evitaba con el empleo de planchas celulares y con la construcción de un sistema parecido a las tejas de ventilación o beatas empleadas en cubiertas tradicionales, realizada en chapa lacada con lamas incluidas en el frente para evitar la entrada de pájaros; se consigue también una renovación del aire interior al producirse una corriente de aire entre las beatas situadas unas frente a otras en los dos faldones de cubierta, impidiendo la formación de bolsas de aire caliente en la parte superior de la cubierta.
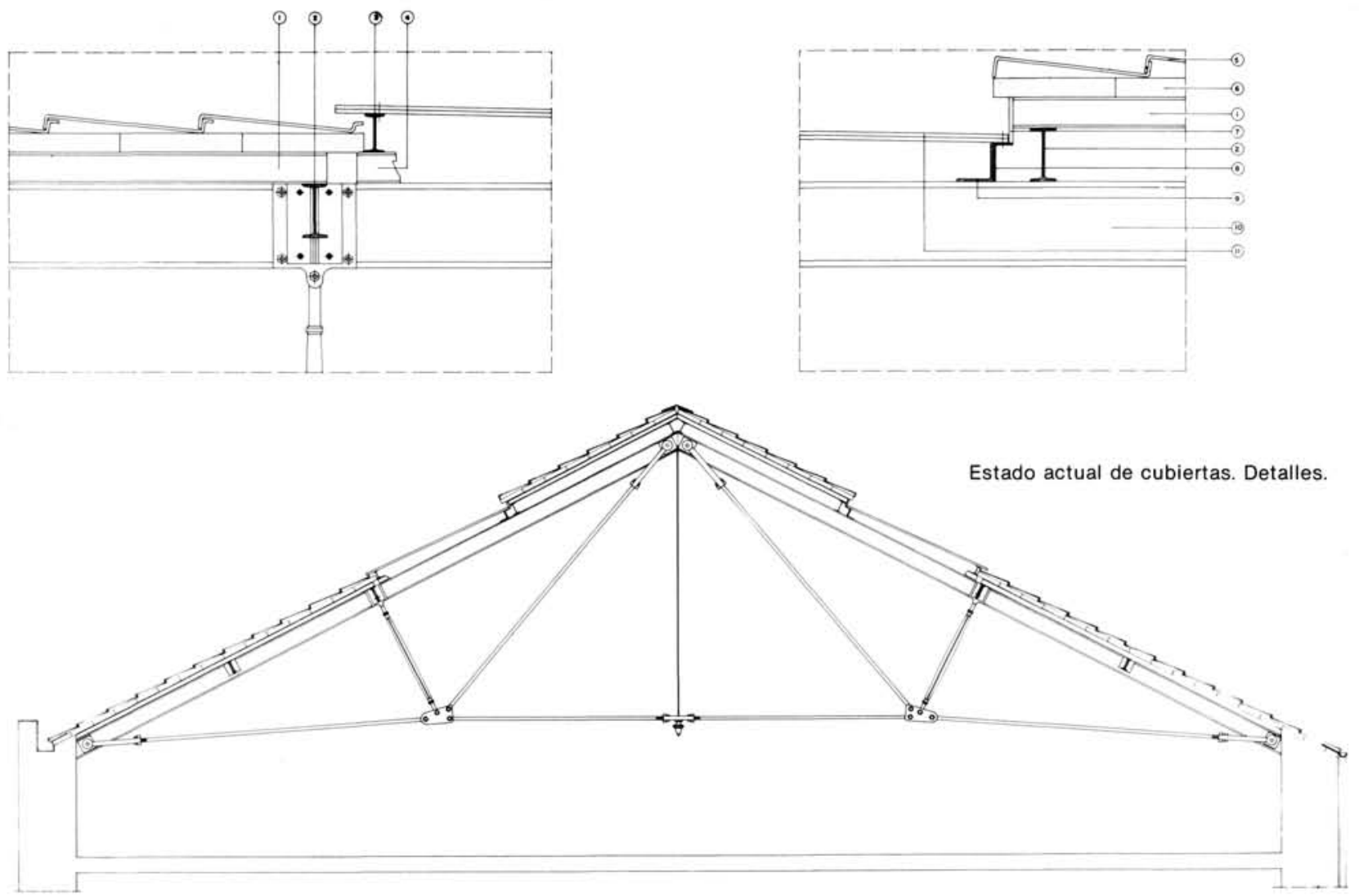

Leyenda: 1.-PerfilI-80. 2.-Correa de perfil I-140. 3.-Perfil I-100. 4.-Separador I-80. 5.-Teja cerámica plana. 6.-Bloque de hormigón armado. 7.-Chapa metálica corrida. 8.-Casquillo de perfil L $100 \times 8 \mathrm{~mm}$. 9.-Perfil LD $100 \times 50 \times 6 \mathrm{~mm}$. 10.-Correa de perfil I-220. 11.-Lucernario de plástico. 

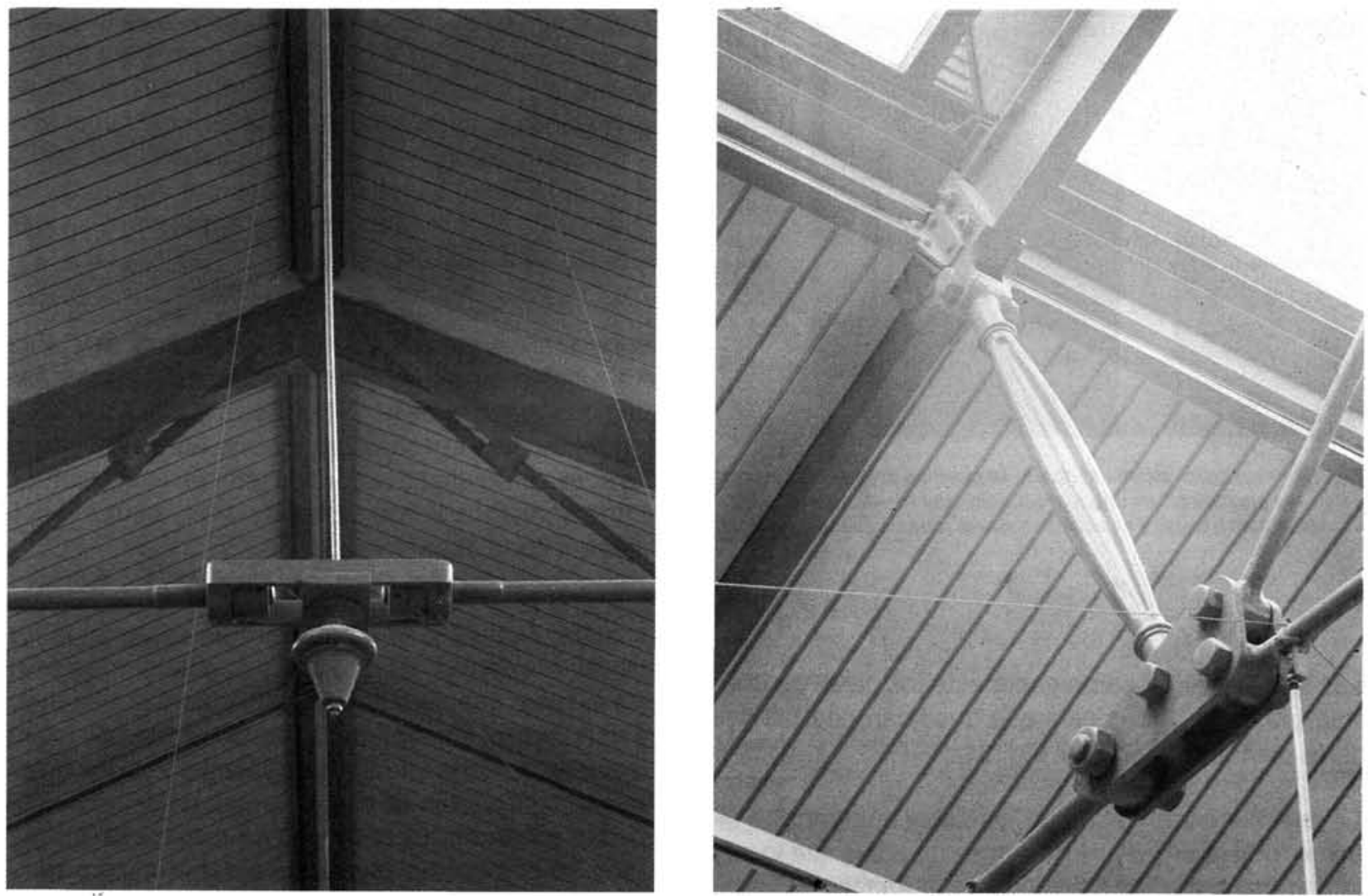

Figs. 33 y 34.-Detalle de la cercha (pendolón y tirante).

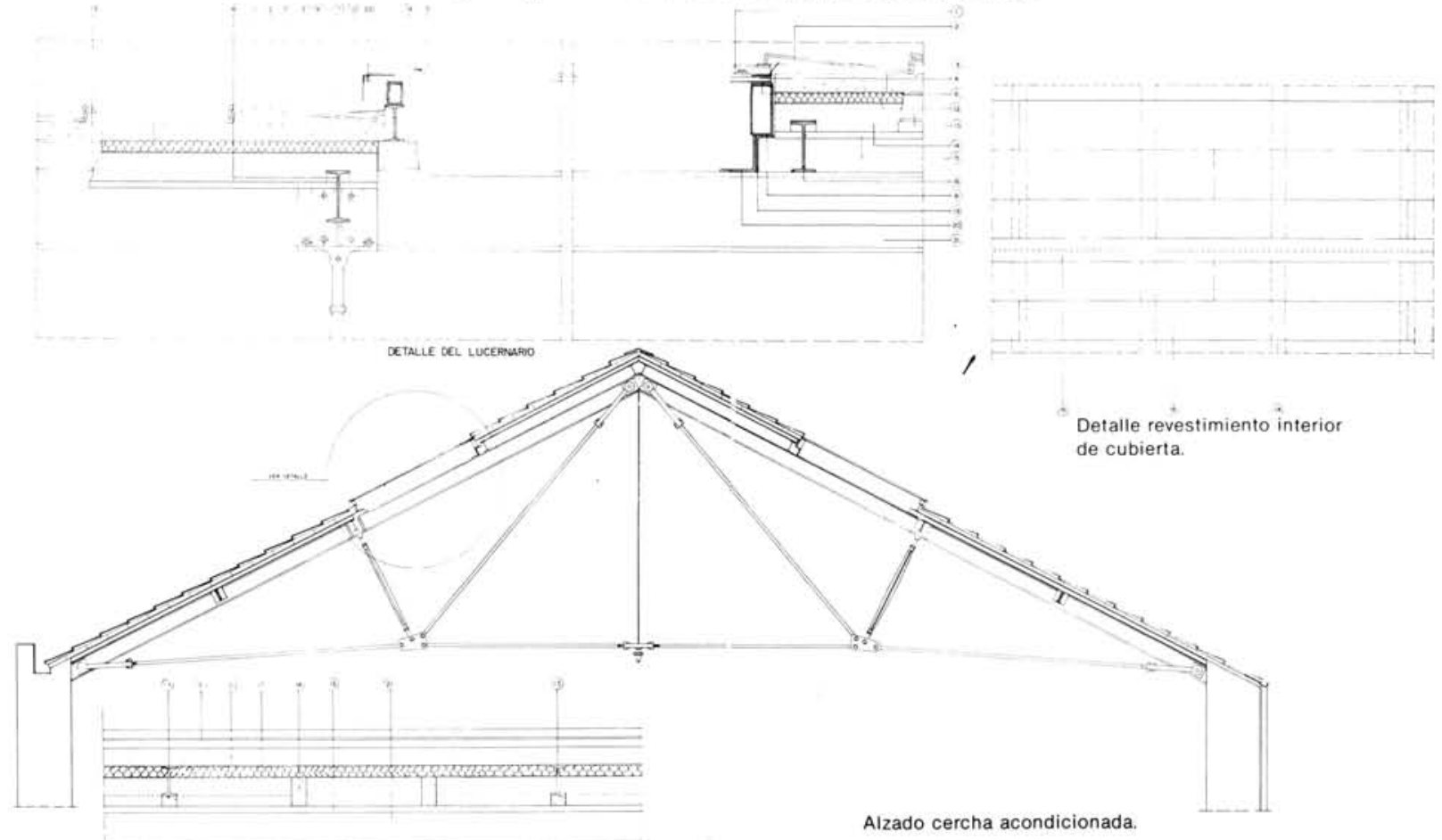

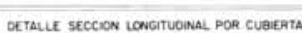

Leyenda: 1.-Regleta de perfil en " $U$ " de aluminio. 2.-Teja plana cerámica primitiva. 3.-Regleta de perfil en " $U$ " invertida lacada, con objeto de tapar la unión entre planchas de plexiglas. 4.-Plancha de polimetacrilato de metilo celular marca plexiglas SDP $16 \mathrm{~mm}$, color blanco opal. 5.-Tornillo de acero autorroscante. 6.-Goma piramidal. 7.-Remate rigidizador. 8.-Perfil hueco rectangular de $140 \times 60 \times 5 \mathrm{~mm}$. 9.-Perfil hueco rectangular de $60 \times 40 \times 4 \mathrm{~mm}$. 10.-Pieza sostén plancha plexiglas. 11.-Bloque de hormigón armado primitivo. 12.-Aislamiento térmico en planchas rigidas de poliestireno extruido de $3 \mathrm{~cm}$ de espesor. 13.-Parecillo de perfil de hierro I-80 primitivo. 14.-Perfil auxiliar de aluminio de $80 \times 40 \mathrm{~mm}$. 15. - Chapa perfilada nervada de $1 \mathrm{~mm}$ de espesor. 16. - Correa de perfil = 140 primitiva. 17. - Perfil l-100 primitivo. 18.-Separador de perfil I-80 primitivo. 19.-Perfil LD $100 \times 50 \times 6$ primitivo. 20.-Casquillo de perfil L $100 \times 8 \mathrm{~mm}$ primitivo. 21.-Par de perfil $1.220 \mathrm{~mm}$ primitivo. 22. - Perfil de cierre "U" en aluminio. 


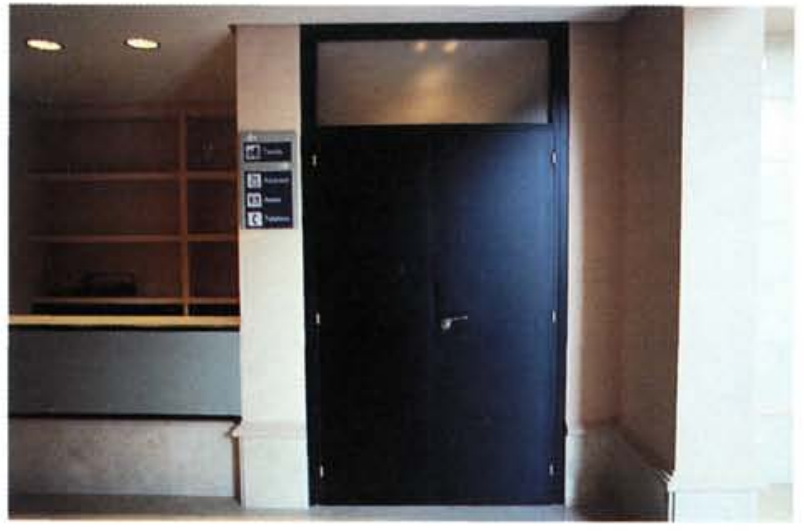

Fig. 36.-Vestibulo reformado donde se clarifica el espacio y se aprovecha ele eje para situar una reproducción del triceratops. Se ubican espacios para tiendas y se accede a nueva zona de aseos y servicios.

Las beatas se colocaron encima de los pares de la es. tructura de la cercha para que quedaran ocultas desde la planta inferior. (Ver Fig. 34).

La demolición del techo de las salas nos permite eliminar toda la estructura de pilares de acero que lo sostenian, ganando las salas en visión espacial.

La idea generadora de todo el proyecto es conseguir una nave contenedor; para ello es fundamental eliminar la mayor cantidad posible de pilares que son un im. portante obstáculo visual. (Ver Figs. 13 y 14).

También es demolida la fila de pilares intermedios que sostiene la entreplanta en galeria. (Ver Figs. 15 y 16).

Colocamos una serie de vigas HEB-220 transversales entre los pilares extremos a lo largo del forjado de la entreplanta, de tal forma que la carrera continua que apoya en los pilares interesados, al eliminar éstos, transmitiesen la carga puntual al nuevo perfil. (Fig. 25).

El montaje de los nuevos perfiles tenía que realizarse sin demoler el forjado de la entreplanta por razones económicas.

Se procedió a apear la carrera continua. A continuación se cortó ésta en tramos para poder introducir la nueva viga por debajo del forjado, rompiendo éste solamente lo necesario para colocar aquélla, volviendo a soldar la carrera suplementada con casquillos del mismo perfil que ésta, a la nueva viga. (Ver Fig. 23).

Con la desaparición de los pilares intermedios, la carrera queda dividida en tramos de mayor luz que antes; si a esto añadimos que en el futuro las sobrecargas a soportar por el forjado serán importantes, ya que está prevista la colocación de vitrinas de gran peso, hacia imprescindible realizar un ensayo de carga.
El resultado es que el forjado primitivo no es capaz de resistir las sobrecargas que prevé la norma MV-101, para este tipo de edificios, ya que la carrera existente de acero tiene un módulo resistente inferior al necesario. Se procedió entonces a reforzar la carrera colocando un perfil HEB-140 a un lado de ésta, por debajo de las viguetas del forjado, y con apoyos en las nuevas vigas HEB-220. (Ver Fig. 24).

De los análisis del acero de la estructura, ya existente en el edificio, se obtuvo que contenía cantidades de carbono que variaban de unos perfiles a otros, aceptando alguno de ellos la soldadura y otros no. Esto supuso una nueva dificultad a la hora de reforzar la estructura, ya que debíamos ir comprobando si el acero era soldable en cada caso.

El cristal elegido está compuesto de dos vidrios formando una cámara de aire con vaciado interior; el vidrio exterior consiste en una luna coloreada en bronce tipo Parasol con objeto de reducir el paso de las radiaciones; el vidrio interior transparente. Para los revestimientos interiores se eligieron materiales nobles de madera y mármol. La tarima es de madera de Elondo $y$, con su colocación volviamos a dar el mismo tratamiento que tuvo en su origen el edificio. El mármol se utilizó en las escaleras y para marcar los ejes de paso y zonas de máxima circulación, asi como los rodapiés y zócalos.

En las paredes se eligió pintura plástica acabando con gota fina aplastada.

\section{AGRADECIMIENTOS}

La realización de la obra es consecuencia de la colaboración prestada por todas las personas que han intervenido, y que constituyen el equipo.

Algunas soluciones adoptadas sobre la marcha han sido aportaciones personales de especialistas y han permitido mejorar aspectos concretos de la obra.

Augusto Vázquez, aparejador imprescindible en los dificiles comienzos, ERCO iluminación en todo momento, y los ingenieros de IBERDUERO, S .A., Sanchez Sudón y Antonio Oviedo, que realizaron el estudio de es. tabilidad del edificio, fueron parte del conjunto de personas y entidades que colaboraron en la realización de la obra.

EI CSIC continúa la actuación con la rehabilitación del Museo de Zoologia y la creación de nuevos laboratorios y edificios que completen este conjunto. 